\title{
Ancillary Services Market Design in Distribution Networks: Review and Identification of Barriers
}

\author{
Konstantinos Oureilidis ${ }^{1, *(D)}$, Kyriaki-Nefeli Malamaki ${ }^{1}$, Konstantinos Gallos ${ }^{2}$, \\ Achilleas Tsitsimelis ${ }^{2}$, Christos Dikaiakos ${ }^{2}$, Spyros Gkavanoudis ${ }^{1}$, Milos Cvetkovic ${ }^{3}$, \\ Juan Manuel Mauricio ${ }^{4}$, Jose Maria Maza Ortega ${ }^{4}$ (D), Jose Luis Martinez Ramos ${ }^{4}$, \\ George Papaioannou ${ }^{2}$ and Charis Demoulias ${ }^{1}$ \\ 1 Department of Electrical and Computer Engineering, Aristotle University of Thessaloniki, \\ 54124 Thessaloniki, Greece; kyriaki_nefeli@hotmail.com (K.-N.M.); s.gkavan@gmail.com (S.G.); \\ chdimoul@auth.gr (C.D.) \\ 2 Independent Power Transmission Operator, 10443 Athens, Greece; kostas.gallos90@gmail.com (K.G.); \\ a.tsitsimelis@admie.gr (A.T.); c.dikeakos@admie.gr (C.D.); g.papaioannou@admie.gr (G.P.) \\ 3 Department of Electrical Sustainable Energy, Delft University of Technology, 2628 CD Delft, \\ The Netherlands; m.cvetkovic@tudelft.nl \\ 4 Department of Electrical Engineering, University of Seville, 41092 Seville, Spain; jmmauricio@us.es (J.M.M.); \\ jmmaza@us.es (J.M.M.O.); jl.martinez.ramos@gmail.com (J.L.M.R.) \\ * Correspondence: oureili@yahoo.gr; Tel.: +30-2310-995-960
}

Received: 30 December 2019; Accepted: 13 February 2020; Published: 18 February 2020

\begin{abstract}
The high proliferation of converter-dominated Distributed Renewable Energy Sources (DRESs) at the distribution grid level has gradually replaced the conventional synchronous generators (SGs) of the transmission system, resulting in emerging stability and security challenges. The inherent characteristics of the SGs are currently used for providing ancillary services (ASs), following the instructions of the Transmission System Operator, while the DRESs are obliged to offer specific system support functions, without being remunerated for these functions, but only for the energy they inject. This changing environment has prompted the integration of energy storage systems as a solution for transfusing new characteristics and elaborating their business in the electricity markets, while the smart grid infrastructure and the upcoming microgrid architectures contribute to the transformation of the distribution grid. This review investigates the existing ASs in transmission system with the respective markets (emphasizing the DRESs' participation in these markets) and proposes new ASs at distribution grid level, with emphasis to inertial response, active power ramp rate control, frequency response, voltage regulation, fault contribution and harmonic mitigation. The market tools and mechanisms for the procurement of these ASs are presented evolving the existing role of the Operators. Finally, potential barriers in the technical, regulatory, and financial framework have been identified and analyzed.
\end{abstract}

Keywords: ancillary services; distributed generation; renewable energy resources; electricity markets; distribution grid; inertia response; primary frequency response; voltage regulation; fault contribution; harmonics mitigation

\section{Introduction}

Following the conventional design of the electricity system, the power from the large generators is carried to the transmission systems, while the distribution grid is responsible for the electrification of the loads connected to the medium voltage (MV) and low voltage (LV). The frequency and voltage are mainly controlled by the bulk generators by means of providing certain advanced services to the transmission system [1]. However, this centralized approach is becoming outdated, since Distributed 
Generators (DGs) and, more specifically, Distributed Renewable Energy Resources (DRESs) are connected within the transmission and distribution system, causing the gradual decommissioning of the conventional synchronous generators (SGs). This trend results in stability and reliability challenges for grid operators. The problem is becoming more severe considering that the majority of the DRESs are converter-dominated-in some cases, with the absence of any rotational masses, and hence, do not have technical predispositions to provide Ancillary Services (ASs). Furthermore, the DRESs have a highly volatile and intermittent nature due to the dependence on weather conditions. As a result, the whole philosophy of the provision of certain services to the grid operators should certainly be revised.

Currently, ASs are services mainly provided by SGs in order to ensure the system security and energy supply with high quality standards [2]. The Transmission System Operators (TSOs) are responsible for procuring and using ASs in their scheduling and dispatch of generation as well as during the real-time system operation. ASs are provided through the efficient procurement (when applicable) to the TSOs by third parties (generators, storage, and flexible loads). Through the liberalization of the electricity markets, the role of the ASs has been advanced, since Balancing Service Procurement (BSP) entities submit their bids for providing ASs to the TSOs. Specific requirements for the eligibility of the AS providers are set appropriately in the National Codes [3,4], with the main target of keeping the frequency and voltage within specific safe bands and restoring their values to the normal range after an imbalance occurs. Accordingly, the main categories of AS refer to frequency response, voltage control and black-start capability [5]. According to reference [6], many differences are identified among the types of procurement of AS in several EU and non-EU countries, as well as the way of remuneration of the AS.

The common report by the ENTSO-E and several EU/DSO entities (E.DSO, Eurelectric, etc.) defines AS as services provided to DSOs and TSOs to keep the operation of the grid within acceptable limits for security of supply and delivered mainly by third parties (i.e., active power control for frequency control, reactive power for voltage control and black-start capabilities) or by the TSOs and DSOs themselves (topology changes and integrated network components) [7]. However, similar to the ASs already referred to, some new ones can be provided by DRESs at both the transmission and distribution system level, as already proposed in the literature and prescribed in recently issued guidelines and standards. In many cases and especially in distribution grid level, these ASs are considered to be system support functions specified for DRESs [8], meaning that these services are not remunerated but are considered as mandatory for the DRES connection at the transmission and distribution system level. Some examples are the Fault Ride-Through (FRT) capability and the voltage support through reactive power control. Other types of ASs, recently introduced or proposed according to the new operational environment, can be found in [9].

In this paper, the current AS structure is analyzed, while new ASs procured by DRESs connected both to the distribution and transmission system are proposed. In the literature, the review papers are either focused on the system requirements for increasing the DRESs' capacity, without elaborating the need for the provision of new remunerated ASs $[10,11]$ or deal with a specific AS from DRES, such as the provision of flexibility [12], frequency [13,14], and voltage AS [15,16]. Other review papers provide a more market-oriented approach, such as references [17,18], while in reference [19], the coordination among the distribution and transmission systems are presented in a conceptual way. A more recent and mature review paper [6] recognizes the importance of the provision of ASs; however, its focus lies on ASs from HVDC systems. On the other hand, this paper not only presents a more comprehensive review on existing ASs but proposes specific solutions for the engagement of new ASs from DRESs both at the distribution and transmission grid level in order to energize the modern grids with a high DRES penetration. In addition, the paper identifies the possible technical, regulatory and financial barriers that currently impede the adoption of these new ASs. Finally, the paper provides suggestions for lifting those barriers that will enable the procurement of emerging ASs from DRESs connected in a distribution grid. 
This paper is structured as it follows: the existing ASs with the current market practice are analyzed in Section 2, considering the different models in EU and indicative non-EU countries. From this comparison, certain differences are presented in order to highlight the different approach for the procurement of these ASs following the TSOs requirements. In Section 3, new ASs, especially in distribution grids, are proposed, since the modern grids face the technical issues due to high hosting capacity of DRESs. These ASs include the inertial response, active power ramp, frequency response, voltage control, fault reaction, harmonics mitigation and their integration in the upcoming smart grid/microgrid concept. The role of the Energy Storage Systems (ESSs) by means of installing batteries and use of Electric Vehicles (EVs) is also considered. In Section 4, an emphasis on the proposals on market mechanisms and tools are described, where the emerging role of the DSO as a central counterparty for the procurement of an AS is reflected. Finally, Section 6 investigates the potential technical, regulatory and financial barriers and obstacles for adopting the new ASs.

\section{Existing ASs and Respective Market Design}

According to the current market structure, ASs are offered by the conventional SGs to the TSOs in order to satisfy specific power system requirements (e.g., keep the frequency and the voltage magnitudes within preassigned limits). According to reference [7], ASs are classified as (i) frequency ASs (mainly for balancing); (ii) services for congestion management; and (iii) non-frequency ASs, such as voltage control and grid restoration. The NREL Report of [20] considers also black-start and voltage support as "Other Essential Reliability Services" and recognizes the inertial response and the primary frequency response as "Frequency-Responsive Reserve Requirements." A high-level description of the most common types of ASs provided by conventional units in EU is provided below.

\subsection{Overview of Existing ASs}

\subsubsection{Frequency Control}

This service restores the frequency in the nominal operating level of $50 \mathrm{~Hz} / 60 \mathrm{~Hz}$ after any deviation occurrence due to physical imbalance between generation and demand. This becomes feasible by adjusting the active power reserves of the system through automatic and rapid responses. The TSOs need to plan ahead in order to ensure that the correct levels of active power reserves are available in real-time, and in case of a shortfall, the TSOs must take remedial actions. Active power reserves include generator units, storage and in some cases demand response. The main ASs offered for frequency restoration are $[16,21,22]$.

I. Frequency Containment Reserves (FCRs)/Primary Frequency Control: FCR is the first control action to be activated, usually within $30 \mathrm{~s}$, in a decentralized fashion over the synchronous area.

II. Frequency Restoration Reserves (FRRs)/Secondary Frequency Control: FRR is the centralized automated control, activated from the TSO in the time interval between $30 \mathrm{~s}$ and $15 \mathrm{~min}$ from the imbalance occurrence. FRR can be distinguished in reserves with automatic activation (automatic Frequency Restoration Reserves-aFRR) and reserves with manual activation (manual Frequency Restoration Reserves-mFRR).

III. Replacement Reserves (RRs)/Tertiary Frequency Control: RR is a manual control. Typical activation time for RRs is from $15 \mathrm{~min}$ after the imbalance occurrence (in Continental Europe) up to hours after.

\subsubsection{Voltage Control and Reactive Power Supply}

The TSO is enforced to keep in balance the voltage across the system ensuring stability and avoiding possible damage of the connected equipment or disconnection of power generating modules [23]. Specific obligations of TSOs regarding voltage limits, for high and extra high voltage, are defined in the Network Codes on System Operation [4,24]. To achieve this desired voltage profile, reactive power 
(leading or lagging) is required to be injected at specific locations of the network through controllable devices, such as generating units equipped with Automatic Voltage Regulators (AVRs) and Static VAR Compensators (SVCs). These actions have to take place relatively close to the voltage deviation point by providing the required reactive power locally. Generally, the voltage control actions are distinguished at European power systems in a three-level hierarchy based on their activation time: (i) Primary voltage control (local automatic control which is activated within milliseconds and can last up to one minute); (ii) Secondary voltage control (centralized automatic control action one minute after the voltage deviation and can be maintained for several minutes); (iii) Tertiary voltage control: (10-30 min after the voltage deviation occurrence, optimization of network losses taking into account the reactive power reserves). In general, the countries do not differentiate the voltage control layers nowadays.

\subsubsection{Black-Start Capability/Grid Restoration}

Black-start is the AS provided by generating units (black-start units), which are able to inject energy into the system, without any electrical energy supply external to the power generating facility, following a general or partial system operation interruption (shutdown) [24]. Once these units have energized the network, they will serve to facilitate the start-up of other generators, in order to stabilize the system normal operation faster. In addition, these units should be also able to consume and produce reactive power, in order to control the voltage. Since most power stations are not able to restart without an additional external supply, the ability of some units to perform black-start is necessary to achieve the re-establishment of the power supply. Technologies used include pumped storage, interconnections, hydro plants, gas and nuclear units, either connected to the transmission or the distribution network, while in some Nordic countries the TSO owns units for black start service.

\subsection{Conventional AS Market Design}

The AS market facilitates the trading of services and improves the competition among different involved stakeholders. Generally, the TSO is the operator and sole purchaser of products in the AS market, while sellers include the prequalified generators and in some cases demand response (involving large consumers and aggregators) and storage facilities. AS offers are long-term, usually annual, while the available capacity is offered on a daily basis. Three main balancing processes exist in the AS markets: central dispatch, self-dispatch portfolio-based and self-dispatch unit-based. According to reference [22], the central dispatch regards a scheduling and dispatching model, where the generation and consumption schedules are determined by the TSO within the Integrated Scheduling Process. In the self-dispatch portfolio-based model, the aggregated generation schedules and consumption schedules are determined by the scheduling agents of these facilities. Finally, in the self-dispatch unit-based model, each power generating and demand facility follows their own generation or consumption schedules.

The procurement methods can be divided in four main categories: compulsory provision, bilateral contracts, tendering and spot markets [16]. In compulsory provision, a class of generators are engaged to provide specific reserves of AS. This engagement rises through the national regulations and network codes, which mandate specific sources of AS to connect to the system. In the case of bilateral contracts, the TSO negotiates with each provider the quantity and price of the offered AS. This allows the TSO to buy only a specific AS amount and to deal with sellers in order to minimize the overall cost. However, these contracts are usually long-term and possible market conditions changes cannot be taken into account. The last two methods, tendering and spot market, refer to an AS exchange process characterized from increased competition. The former usually includes long-duration services, while the latter involves shorter and less standardized products [16].

Another distinction between the AS provision can be found in the remuneration approaches $[9,16]$. Primarily, the ASs can be non-remunerated at all, meaning that they are considered as mandatory support functions provided by the sources. If this is not the case, the ASs can be paid through a regulated price, a pay-as-bid price or a common clearing price. In the first approach, the regulated price is set by the regulator or the TSO. Nevertheless, this method does not reflect perfectly the actual 
provision cost. In the pay as bid pricing scheme, the provider receives the price of the accepted offer. Finally, when remuneration is based on the common clearing price, the succeed sellers are paid the price of the most expensive accepted or the least expensive rejected offer. Further, remuneration includes several components that reflect the different costs of the provision entity. To start with, the fixed allowance and the availability price refer to the cost of the seller to make a specific amount of ASs available. Later on, the utilization payment and the utilization frequency cost reflect the actual exploitation of the product and the extra cost that may arise each time that the provider is called upon (in a specific period of time), respectively. Finally, the remuneration takes into consideration the opportunity cost that reflects the possible profit loss in the case where the provider could have sold other products instead of the respective ASs.

\subsubsection{Frequency Control}

Concerning the procurement methods of frequency control, all the aforementioned approaches are applicable within EU countries. The same applies for the different remuneration types, which are interlinked with the procurement process. In Table A1, the frequency reserves in several EU countries are presented based on the information provided in reference [22], reflecting the different regulatory framework of each EU country. As it is presented, there are many different types of frequency reserve procurement entities, while their nominal power can vary significantly. In some countries, like Greece, the providers of all frequency services are only the generators, while in other countries the pump storage, the load, and the batteries can also provide such kind of services. Furthermore, in some cases like Denmark and Austria, different providers are for FCR and different are the providers for FRR. By comparing the data of this table with the previous report of ENTSO-E [22], the role of the energy storage and more specifically of the batteries in the procurement of frequency AS is enhanced.

\subsubsection{Voltage Support}

From the AS providers' point-of-view, the reactive power support can be distinguished in compulsory and enhanced. The first case falls into the compulsory requirements that each generator should fulfil for its connection and concerns units that exceed a pre-specified capacity. The latter refers to non-mandatory additional voltage regulation services. With regard to the remuneration, settlement rules are similar to those of frequency reserves. However, this AS is not remunerated in all countries of EU. In the case of remuneration, settlement rules are similar to the frequency reserves (pay-as-bid, marginal pricing or regulated price). In Table A2, the voltage control as an AS in several EU countries is presented based on the information provided in reference [22]. The providers of voltage control can be synchronous generators, windfarms, photovoltaic (PV) systems (only in Spain and France), HVDC links, assisted by devices operated by the TSO such as SVCs, FACTS, capacitor/inductor banks, etc. From the available data, different entities can be providers of the voltage control service following the national regulatory framework. Furthermore, in some EU countries, this service is also paid by the TSO.

\subsubsection{Black Start}

From an AS market perspective, this AS exists in the majority of countries. In some of these countries, black-start is mandatory for predefined conventional power plants, while in others there exist bilateral contracts and the eligibility selection is based on a number of characteristics, such as geographical distance and capacity and in some cases regulated gradient (ramping rate). However, black-start is seldom clearly defined, provided and remunerated. With respect to the remuneration, when available, is enabled through similar schemes as the ones described above, namely regulated, pay-as-bid, or marginal pricing. The providers of restoration services can be distinguished between AC power generating modules and HVDC systems [16], according to the EU network code for electricity emergency and restoration. Table A3 in Appendix A provides details referring to the black start for the different EU countries based on the information provided in reference [22]. In many EU countries, this 
service is mandatory mainly from the hydro power plants and the hydro storage power plants. In other cases, this service is a bilateral agreement between the services provider, which can be a generator, and the TSO. Regarding the voltage level, all countries provide this service in transmission grid, while in some cases (such as Croatia, Finland, France, the UK, etc.), the provision of the black-start concerns both the transmission and distribution grid.

Table A4 presents an analysis of the frequency services, the voltage regulation and black-start as an AS for some non-EU countries [9]. These markets operate in a different way compared with EU markets concerning both the description of each service and the implemented procurement methodologies.

\section{New Emerging ASs to Be Offered by DRESs and Procurement Schemes}

\subsection{New Emerging ASs}

The increasing penetration of DRESs in the distribution and transmission grids has created the need for new type of AS similar and complementary to the ones defined above. In contrast with the current power system operation, where the large conventional generators are the main sources for maintaining the system reliability, the DRESs in near future would constitute an alternative choice by providing ASs to the grid. A significant reason for investigating novel ASs in the transmission system is the emergence of additional challenges, especially the ones affecting the grid security, due to the increased RES penetration. Particular attention on this issue has been already given in weak grids, which may suffer from stability issues, hence, need more special treatment. Therefore, new ASs are currently provided or proposed to be introduced in these networks, which are not common in highly interconnected systems mainly powered by conventional generating units. However, such cases could serve as the basis for establishing new standards for the implementation of similar ASs in every network that is subject to the future changes in the generation mix. Such an example is the grid code of Puerto Rico [25], where new technical requirements for the DRESs are described. Following is a comprehensive review of the novel types of AS either proposed or already applied in particular weak grids and systems with high DRES penetration by the future markets. The new ASs and the existing ones are illustrated in Figure 1.

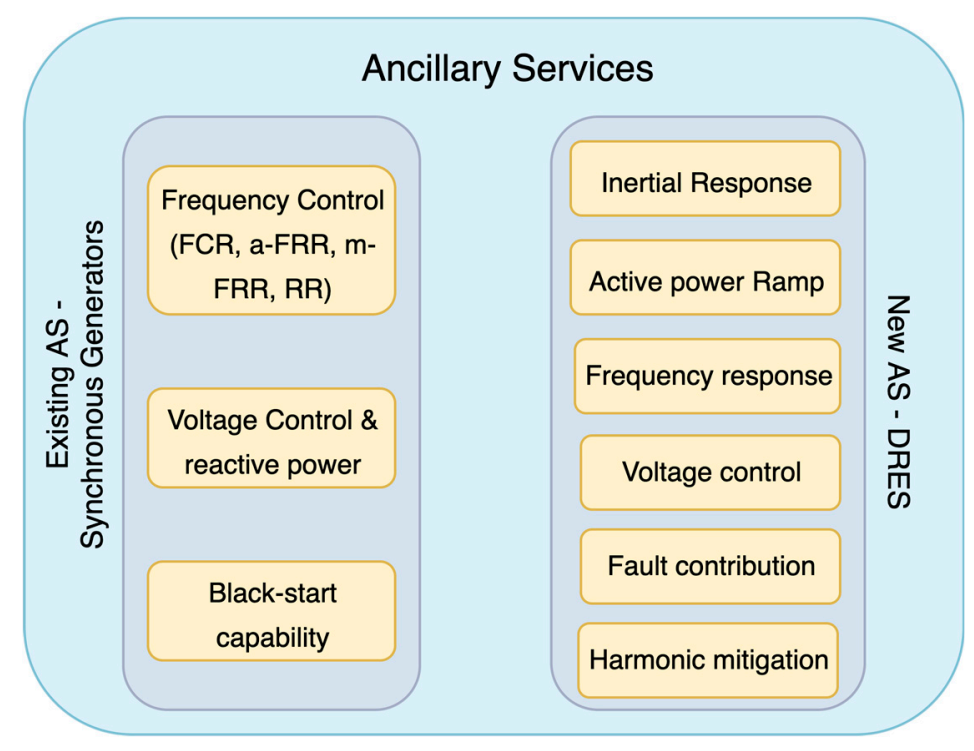

Figure 1. Existing and new ancillary services (ASs) provided by the synchronous generators (SGs) and Distributed Renewable Energy Sources (DRESs), respectively. 


\subsubsection{Inertial Response}

Inertia is an inherent characteristic of conventional synchronous generators (SGs) due to their rotating masses that prevents fast frequency variations in the first few cycles after a power imbalance. DRESs will gradually replace conventional SGs in the near future in order to reach the worldwide targets for reducing carbon emissions. Inevitably, as a side effect, this will lead to certain frequency stability issues, since those units are mostly converter-interfaced and provide inherently little (e.g., doubly fed induction machines) or no (e.g., photovoltaics) inertia to the system [26]. The particular issue has been examined in reference [27], where a power system simulation was conducted by the Western Electricity Coordinating Council of the USA for the case of high penetration of wind generation and fossil fuel generation withdrawal, leading to noticeable system frequency response degradation. Furthermore, the analysis for the German power system inertia for the year 2013 has shown a reduction in grid inertia time constant to half of its original value, at the same time when $50 \%$ of the energy sharing was provided by PV and wind generators [28].

Therefore, making DRESs behave in a way similar to SGs in terms of inertial response is highly recommended in order to ensure stable grid operation in the future. The particular feature, commonly known as virtual or synthetic inertia, has been proposed as a service in several cases. For instance, the simulations in reference [26] have shown that it is economically and technically possible for the wind plants to provide an emulated inertia resulting to an even better inertial response compared to the case with no wind plants connection. Additionally, there exist new types of variable-output DRESs with the ability of providing controllable virtual inertial response and/or primary frequency response. As an example, commercial wind turbine manufacturers, like WindINERTIA [29], ENERCON [30], and General Electric [31], already provide virtual inertia response features. Furthermore, a real-case requirement was set in a procurement request of Hydro Quebec, a Canadian utility, regarding $2000 \mathrm{MW}$ of wind turbines in 2005, where the wind farms should have had the ability to operate like a machine with an inertia constant of $3.5 \mathrm{~s}$ [32]. Contrary to wind turbines, inherently PV units cannot provide inertial response based on their own primary source. However, this could be possible through the coordinated use of an appropriate fast-acting ESS, e.g., flywheel, supercapacitor, or battery [33].

In reference [34], the Virtual Synchronous Machines (VSMs) concept is proposed in the context of the smart grid environment for providing inertia and damping behavior together with cascaded voltage and current controllers. Detailed reviews on the several models of VSMs appear in references [35-37]. In reference [35], several converter topologies, e.g., Virtual Synchronous control (VSYNC) topology, ISE Lab's topology, Institute of Electrical Power Engineering (IEPE) topology, Kawasaki Heavy Industries (KHI) topology, etc., are reviewed. A classification is made in reference [36], where it is stated that the Ise lab's topology, the synchronverter, the droop control and the VSG are the most popular in literature from each classification.

Up to now, there exists no market for trading virtual inertia from converter-interfaced DRES nor inertia from conventional SGs [36]. SGs and some loads (e.g., motors) are treated as a free resource with respect to the provided inertia, since the latter is an inherent characteristic in the power system. As the electric power grids are more and more dominated by converter-interfaced, inertia-less DRES, the requirements for inertial response will become a valuable tradeable commodity, and generating plants will demand financial compensation, since it will be offered virtually by WTGs or even PV systems with ESS technologies [38], (e.g., batteries, super-capacitors, etc.), leading to increased investment and operational cost. An example on the provision of true inertia response by PV plants is shown in Figure 2, where new control methods for the DC/AC inverter of the PV plant have been developed, while a Fast Storage System (FSS) based on supercapacitors is also implemented. It is evident that the provision of synthetic inertia comes at an additional investment cost or the FSS at the DC-link and the DC/DC converter that should be compensated in a future inertia AS market. 


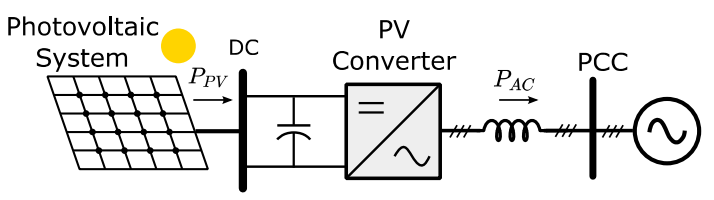

(a)

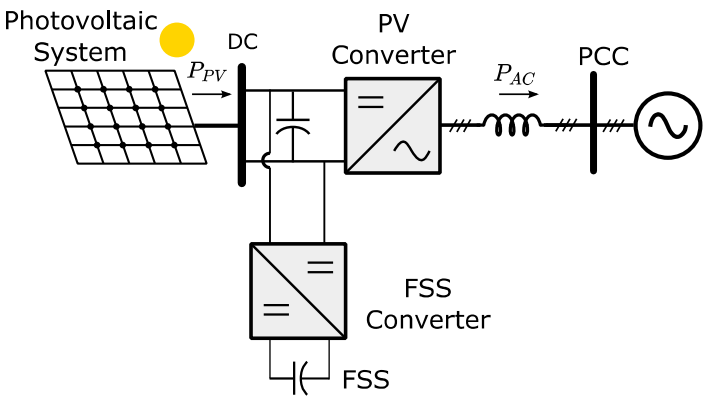

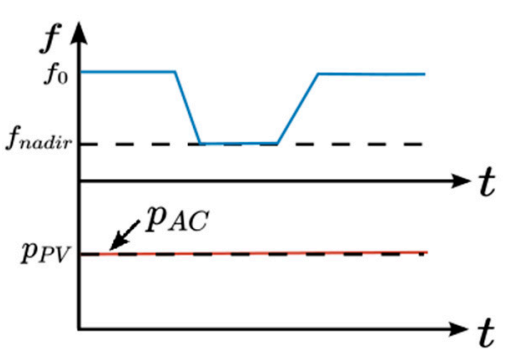

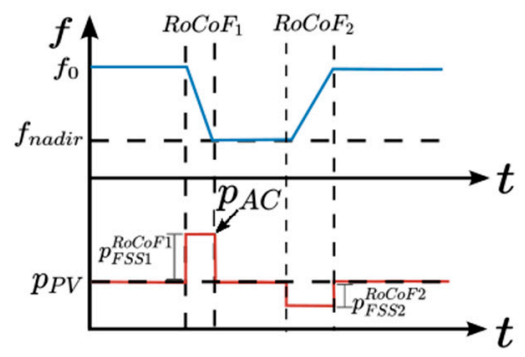

(b)

Figure 2. Illustrative example of a photovoltaic (PV) plant (a) conventionally, without storage at the DC-link and the DC/AC inverter controlled as current source, no inertial response can be exhibited, (b) equipped with a Fast Storage System (FSS) at DC-link, where the DC/AC inverter is controlled as voltage source. In case $(\mathbf{b})$ inertial response can be provided.

A market-based approach can be a cost-effective solution, so as to ensure sufficiency of inertial AS in the future power market [39]. Another possible solution is to operate PV plants below their Maximum Power Point (MPP) with reserve for inertial response with the suitable market structure for such resources. It should be mentioned, however, that such a functionality is actually a Fast Frequency Response (FFR) rather than an inertial response. FFR refers to the ability for rapid variation of the output power within a very small time-frame, i.e., a few hundreds of milliseconds [40]. The difference between FFR and primary frequency response (PFR) is less clear; generally, PFR would reflect a somewhat slower response (but still measured in a few seconds or less). A scheme inertia trading is presented in reference [41], where it is recommended that inertia should be traded in terms of an inertia metric and not in terms of power or energy. A unit commitment framework is proposed in reference [42] for FFR AS in the power system with transient stability constraints, so as to include dynamic performance requirements. It is shown that additional inertia, e.g., additional virtual inertia, enables the system to schedule conventional units with lower costs. Some papers propose a penalty factor for generators without inertial response capability. However, so far, the future operation and structure of an inertia market is still vague and remains an open research area.

One method that can be further explored is deploying inertia as "service" for power quality. The Quality of Service (QoS) metrics, which have already been proposed for cloud computing services [42], can be implemented also for power systems in order to measure power quality in terms of inertial response availability. As an example, a microgrid operator can provide inertial ASs based on certain criteria e.g., maximum allowable Rate of Change of Frequency (RoCoF) and/or frequency deviation. In these conditions, the quality may be evaluated with respect to the response time after a frequency disturbance and/or inertia made available, enabling in this way the microgrid operators to incorporate inertial response ASs in their systems based on the requirements of its end-users. Even though there are not detailed estimations of inertial response requirements except from ERCOT [20], several national grid codes have already set additional services for mitigating the RoCoF in case of a sudden 
imbalance [43]. This service is closely associated with inertial response. Another similar service is the proposed FFR by Eirgrid and the TSO of Northern Ireland (SONI) [44].

\subsubsection{Active Power Ramp Rate Control}

During the last few years, the increased penetration levels of variable RES-particularly wind and solar resources-has led to significant net load variations as perceived by conventional SGs. These variations, mostly appearing in minute-to-hour timeframes, should be considered by the responsible TSOs and should be properly compensated in order to maintain the power balance in the transmission system. The Grid Operator in California (CAISO) reported a typical case of such issue in 2013, as extensive solar penetration has led to the famous duck curve [45]. This problem arises when the solar generation drops to zero during sunset, which is mostly a peak-demand time, making the fast ramping-up of the conventional units necessary in order to serve the power demand and balance the system. However, such a steep rise in ramp rate can significantly increase the price of energy, since it may exceed the ramping capability of the conventional generation [46], pressing the TSOs to re-evaluate their systems' flexibility and ensure sufficient power ramping capability by alternative sources. Another example is the operating reserve demand curves used in US markets (ERCOT, PJM), which essentially increases real-time energy and AS prices creating extreme price spikes in case of reserve scarcity, which in turn is very often caused by large (and usually not well forecasted) renewable generation ramp downs. Such price spikes can hamper the economics of those RES units that are imbalanced. In Table 1, the ramping reserve requirements in CAISO and Midwest Independent Transmission System Operator (MISO) are briefed.

Table 1. Ramping reserve requirements [20].

\begin{tabular}{|c|c|}
\hline CAISO & $\begin{array}{l}\text { Maximum flexible ramp up and down requirements are defined as the } 2.5 \% \text { and the } \\
97.5 \% \text { percentile of net load change } \\
\text { Uncertainty threshold: } \\
\text { Intra-day 15-min market: }-1200 \mathrm{MW} \text { downwards and } 1800 \mathrm{MW} \text { upwards; } \\
\text { Intra-day 5-min market: }-300 \mathrm{MW} \text { and } 500 \mathrm{MW} \text { in both directions }\end{array}$ \\
\hline MISO & $\begin{array}{l}\text { Depends on the sum of the forecasted change in net load and an additional amount } \\
\text { of ramp up/down ( } 575 \mathrm{MW} \text { for now) } \\
\text { Highest hourly average real-time requirement: } 1554 \mathrm{MW} \text { (ramp up) and } 1614 \mathrm{MW} \\
\text { (ramp down) }\end{array}$ \\
\hline
\end{tabular}

Therefore, converter-interfaced RES are widely proposed as a flexible source to provide fast power ramp rate services to the system, since they can effectively adapt their frequency response in order to meet the relevant future requirements set by the responsible TSOs. Over the last few years, research has been devoted to developing new methods for the control of active power ramp rates of RES power plants. This is regarded as an important target set by the TSOs of relatively weak networks to mitigate frequency events that may occur due to the abrupt change of the RES output power [24,47]. This emerging phenomenon will start to affect larger power systems, as the RES penetration increases. Such operation is proposed to be introduced as a new AS into the market in [33], particularly referred to as "Following Reserves." The Midcontinent Independent System Operator (MISO) and CAISO in the United States have already recognized this need, which reinforces the importance for introducing this product. Furthermore, a growing number of grid codes are specifying particular limits to RES generation in order to avoid extreme power ramp rates, especially in weak grids (mostly island systems), e.g., the TSO in Ireland [44,48] and Puerto Rico [25], pose specific ramp-rate limits for PV systems and Wind Farms (WFs) so that frequency deviations are mitigated. Another solution that has been adopted by PREPA is the use of large ESSs at the Point of Interconnection (POI) of the distribution grids with the transmission system to absorb the sudden active power imbalances [49]. A review on the ramp-rate limits imposed by several authorities globally is presented in references [50,51]. 
Until now, ramp-rate control at the distribution grid level (also referred ti as power smoothing) is addressed in the scientific literature as a system support function for power quality reasons in the both transmission and distribution systems [9]. The power smoothing can be achieved by incorporating an ESS with the DG. For example, introduction of the super-capacitor with a DRES to attenuate the high-frequency components of the RES power [52,53]. An example illustrating the AS of ramp-rate control is shown in Figure 3. A wind gust would yield an electrical power variation as shown with red line, if the FSS was absent. The green line corresponds to the case where the FSS is implemented together with a ramp control algorithm in the DFIG converters, where the reduction of ramps is evident. However, to achieve this functionality, the power exchanged by the FSS is shown in Figure 3c. The additional investment and operation cost of the FSS and the associated FSS should be compensated in the frame of this AS. However, the same FSS or part of it can be used for other ASs, like inertia response, which enables the allocation of the cost to multiple ASs. Nevertheless, such cost allocation is subject to future research.

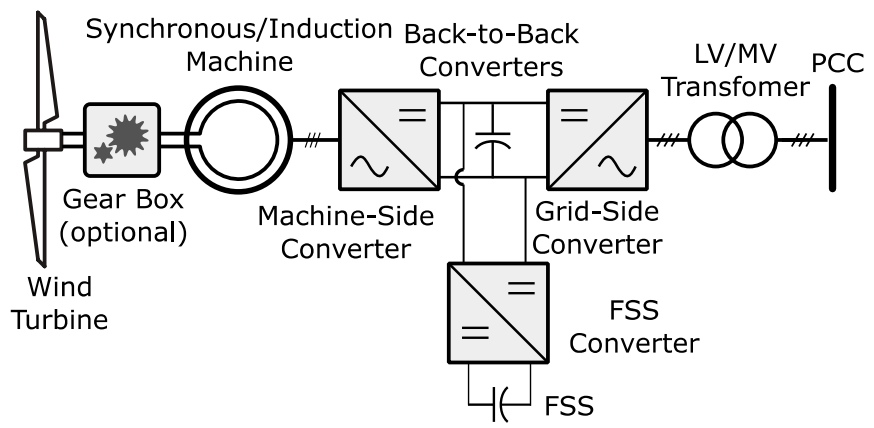

(a)

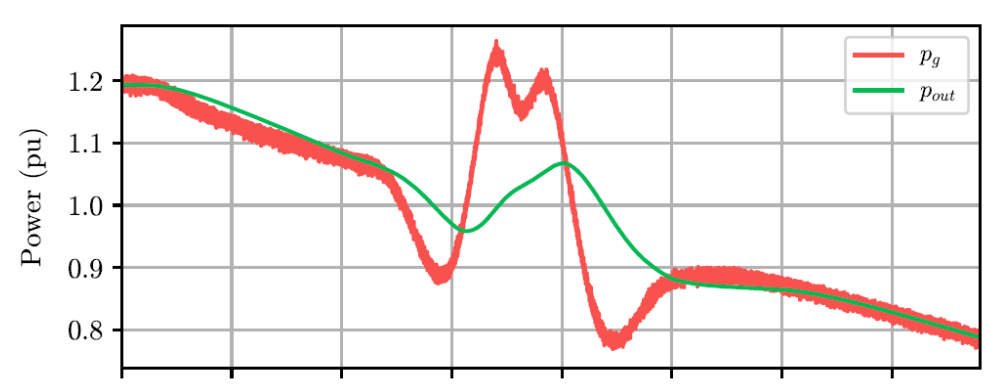

(b)

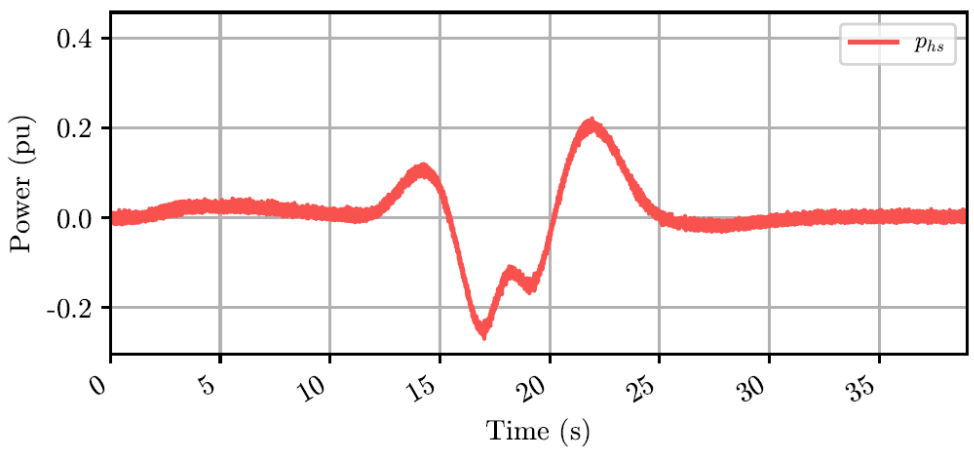

(c)

Figure 3. (a) Illustrative example for the implementation of ramp-rate control in a Doubly-Fed Induction Generator (DFIG); (b) Simulations results of a DFIG-based Wind Energy Conversion System (WECS) under gust event with power smoothing control implemented. Primary source active power $p_{g}$ and active power delivered to the grid, pout; (c) Active power of the FSS, $\mathrm{p}_{\mathrm{hs}}$. 
Battery Energy Storage System (BESS) is also investigated to provide output power smoothing of a PV and wind power generation to attenuate lower frequency components. The efficiency of this solution depends on the BESS technology and its dynamic behavior [54].

\subsubsection{Frequency Response ASs and DRESs Participation}

Until recently, frequency regulation was considered as a service typically provided by large conventional units either automatically or manually, depending on the type of the activated reserves (primary, secondary, or tertiary). However, this situation is rather changing due to the increasing RES penetration in the generation mix, which replaces a significant number of sources being able to provide the aforementioned reserves. As a result, the balancing requirements are increased. According to the recent literature, most studies regarding this issue agree that the demand for frequency reserves in several countries across Europe and the United States has increased nearly up to $10 \%$ of the additional RES capacity over the last few years [55-57]. A paradox seems to be the case in Germany, where despite the extreme growth of wind and solar energy production, the balancing power demand has decreased. According to reference [58], this behavior is mainly attributed to the international and national cooperation among the different TSOs, as well as some important adaptations in the design of the German energy market. Frequency response in the United States has also been deteriorating during the last few years for mainly physical reasons, including excessive governor dead-bands, generators that are not able to offer primary frequency response due to their operational mode (e.g., sliding-pressure mode), and blocked governors [59]. Institutional decisions and lack of incentives by the market have also played their role. More specifically, during the last two decades, the response of Eastern Interconnection (EI) of the United States and Canada has been declining by 60 to $70 \mathrm{MW} / 0.1 \mathrm{~Hz}$ per year [60].

Within this framework, converter-interfaced DRESs could suitably serve as frequency response providers, offering faster ramp rates and greater flexibility to the system through their proper control. By implementing control methodologies, which emulate the behavior of the SGs, the primary, secondary and tertiary frequency control can be provided as AS. The action of DRESs as FCRs can be done by controlling its active power as function of the frequency, i.e., make it operate in frequency sensitive mode (FSM) either in the under- or over-frequency range (denoted also as FSM-U and FSM-O). This is illustrated in Figure 4. Obviously, for the FSM-U mode the DRES must operate with a headroom (i.e., with curtailed power with respect to its maximum power point at a given instant). For this reason, Figure 4 represents a snapshot in time meaning that the headroom can be a proportion of the available maximum power from the primary source which is variable with time. The minimum power in FSM-O depends on the type of the DRES and can be zero for PV plants but for wind plants stability issues determine its value. The various parameters in Figure 4 , such as $\mathrm{f}_{1}, \mathrm{f}_{2}$, the droop slopes, and the frequency dead-band, are configurable and can be set by the TSO/DSO. Recently issued standards and regulations $[24,61,62]$ specify limits for those parameters for new DRES in all voltage levels without however making compulsory the operation of DRESs in FSM-U mode due to the implied lost opportunity cost. It should be mentioned that a converter-interfaced DRES can change its power with frequency very fast, i.e., the slopes of the droops can be quite large. This action is also referred to as FFR but should not be confused with the provision of true inertia.

A DRES that adjusts its electrical power according to a setpoint received by the TSO/DSO without operating in FSM, actually behaves like a FRR or RR, i.e., in secondary and tertiary frequency control. However, in the case of a variable-output DRES, the amount of power variation is not constant as it depends on the primary source. Forecasts are required in such cases so that the TSO knows approximately the available power. Forecasting increases as the time of delivery of this service gets closer. 


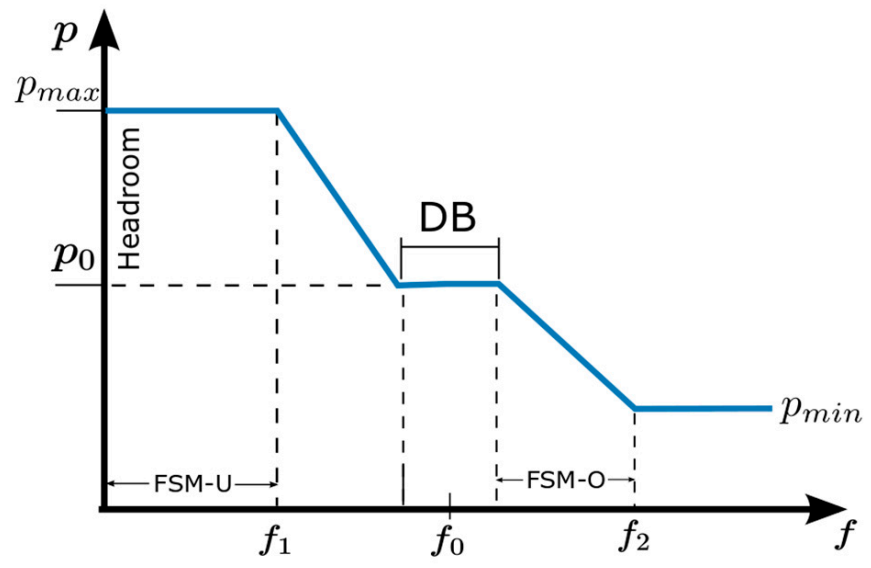

Figure 4. Illustrative example of a DRES operating as a frequency containment reserve (FCR).

The engagement of DRESs as providers of ASs for frequency regulation does not require additional investments in equipment as in the cases of the aforementioned AS. However, it is associated with a rather large lost opportunity cost that needs to be recovered in the frame of an AS market. Furthermore, the upcoming changes in technology may lead particular types of responsive loads and storage units to provide additional reserves. The above services could be offered in the frame of a new AS market, which could be established after setting the necessary requirements in terms of response rate rather than interconnection requirements for generators [33]. A typical case of such new types of products has been applied in Belgium, where Elia, the Belgian TSO, has recently introduced two additional reserve types, namely the R3 Dynamic Profile (R3 DP) and R3 Aggregated Power Plant (R3 APP). These services belong to the wider category of Tertiary Reserves, which is denoted by R3. However, they are separated from the commonly known Replacement Reserves (RR), since R3 DP and R3 APP involve DRES, flexible loads and small energy storage systems instead of large centralized units and interruptible loads, which is the case for RR [63].

\subsubsection{Voltage Control and Reactive Power Support}

In the transmission network, reactive power is usually supplied by conventional SGs relatively close to the location where it is needed since it cannot be transmitted over long distances due to the mainly inductive nature of the lines. This highly prevents the markets from selecting alternative reactive reserve providers, which are far away from the location where the voltage support is needed, in order to offer their services [33]. However, voltage issues can have a cross border impact as they can propagate widely and even cause major generation disconnection, either directly or due to a large frequency deviation [63]. Furthermore, the short-term variability of RES generation is expected to affect significantly the voltage profile of the transmission grid. Therefore, it is becoming important that the grid codes should be enhanced by facing the above challenges and facilitating the participation of RES units in voltage control services.

To this end, ENTSO-E has already set specific requirements for flexible reactive power provision in its System Operation Code, which serves as a contribution towards harmonization of grid codes within Europe [64]. The requirements refer to generating units - both synchronous and non-synchronous and transmission assets, such as synchronous condensers, capacitors/inductors and static VAR compensators. Specifically, ENTSO-E [24] asks for a specific $Q-P$ profile under steady-state conditions from the RES directly connected at transmission system level based on their active power loading and their type (converter-interfaced or directly-coupled). A review of the specifications of reactive power provision at the transmission level can be found in [10]. As it can be observed, not all the grid codes have the same requirements. As stressed out also in [10], it could be interesting to harmonize them in order to develop effective solutions, which is considered as a hard task. 
In North America, the Federal Energy Regulatory Commission (FERC), which is a United States agency responsible for regulating interstate commerce sales and wholesale electricity rates, defined "Reactive Supply and Voltage Control from Generation or Other Sources" as an AS required by transmission-connected providers [33]. PREPA, the TSO of Puerto Rico, has also set reactive power requirements for interconnecting wind and solar generation [25]. Moreover, Eirgrid and SONI in Ireland highlight the need for reliable steady state reactive power control, provided by both synchronous and non-synchronous sources, and propose that the particular product is restructured in a way that incentivizes reactive capability across the widest possible active power range [44].

In some grid codes (especially in weak transmission systems), the regulations for the reactive power support can be divided into two parts [65] - (i) when the grid voltage drops to less than 0.9 p.u., known as FRT grid code requirement, where the power plant should stay connected to the grid during this event and utilize its short-term reactive power capability (dynamic reactive power capability); (ii) when the grid voltage is between the range of 0.9-1.05 p.u. the power plant injects or absorbs reactive power using its steady-state (static) reactive power capability. The need for the dynamic reactive power support was identified as a new product to be provided by WFs in reference [44], since the transient stability of the Irish Transmission system would be significantly compromised. Therefore, the provision of this AS is a new target set by the TSOs to effectively address the technical challenges caused by the increased RES penetration, especially in weak grids. More specifically, in case of a contingency event, e.g., fault, those RES power plants, directly connected to the transmission system, are obliged to remain connected to the grid—referred to as "FRT Capability" —and provide dynamic reactive power support, as imposed by several grid codes [66], especially in weak transmission systems, like Puerto Rico [49] and Ireland [67,68], where large-scale RES power plants are obliged to provide dynamic reactive power up to power factor equal to 0.9 . In some grid codes [66], the dynamic reactive power is also referred as "reactive current injection during faults." The FRT and fault-clearing is analyzed in the following subsection.

The voltage rise problem is particularly sharp at distribution system level due to the reverse active power along the distribution feeders, because their conventional structure is based on unidirectional power flow [69,70]. At distribution system level, current Standards and Grid Codes [61,62,71,72] require several control modes of reactive power of DRES, e.g., $Q(\mathrm{~V}), P F(\mathrm{P}), P F(\mathrm{~V})$, and $Q(\mathrm{P})$ droop curves, which are used for a decentralized voltage regulation, while recent European Standards EN50549 [61,62] allow for a $Q$-setpoint or a $P F$-setpoint to be sent by the DSO. However, this AS is not compensated, because it is considered by the DSOs as a system support function.

There is a big opportunity of developing the voltage control AS market in the distribution network with an active participation of DG, as reactive power cannot be transmitted over long distances. Therefore, it will be technically and economically feasible to perform voltage control locally within a distribution network. In such case, the DG unit should get incentives from the DSO to either spare some capacity or be suitably oversized to provide the reactive power to the distribution network for voltage support. It is quite clear that the voltage control scenario of every distribution feeder is different and therefore the price to provide voltage control services should also be different. A simple and transparent nodal reactive power pricing scheme for both DG units and consumers is presented in [73] that is economically attractive for DG units and fair for consumers and is based on the increased apparent power resulting from reactive power injections. It also makes sure that DG stays in profit, even in the case where DG units are required to curtail their active power production to provide voltage support to the distribution grid. Besides the pricing system, it is also important to develop a complete AS market that defines the exchange rules and provides an incentive to the participant of the voltage control AS market. Such approach is discussed in [73] to provide voltage AS in the distribution network, where a reference signal is generated by the centralized control system in real time and sent to all converters of the DG units that control the reactive power injections in the distributed network. However, this approach cannot provide a good dynamic response to the AS requests and might have a problem with computation time and communication bottlenecks. It 
would be more beneficial, if the AS market would operate locally in the distribution network. A fully distributed computational intelligence-based technique is discussed in [74]. This technique gives RES the ability to provide technical benefits to DSO and can handle AS request of TSO in real-time and can generate extra revenue.

It is also important to make a system that considers the potential benefits for the independent power producers (IPPs) by making sure that all RES units owned by individual IPP can produce the maximum allowable active power. Such coordinated control method is developed in [75] and offers the mandatory voltage control AS. It also avoids the disconnection of RES due to the infringement of voltage regulatory limits. This approach uses both central and distributed coordination, where the DSO sends the power system state signal to IPP and then IPP solves the optimization problem and provide the reference to each RES. It is evident from this review that voltage regulation in the distribution systems is already treated in the scientific literature as a possible AS despite the fact that currently there is not an actual implementation. Although a number of publications suggest financial tools for the remuneration of the reactive power, there is no research on the actual costs of a DRES to supply the required reactive power or the other costs that are deferred when the reactive is supplied by the DRES. The additional losses incurred on the DRES converter when providing reactive power is studied in [76].

\subsubsection{FRT Capability and Fault-Clearing}

The FRT capability mostly depends on the reactive power control and the grid coupling technology. In general, FRT requirements are set by the voltage and time duration profiles that define the requirements for the power generator to ride through grid faults without disconnection. The FRT capability of the DRES is considered in the literature. The FRT is usually provided by the wind turbines, since they have fast response times and can easily recover after a fault event by releasing energy back to the grid [52]. A review of low-voltage FRT strategies for various types of wind turbines is presented in [77-79]. During the last years, where the DG penetration has increased significantly, the grid operators demand FRT responses also from converter-interfaced DRES, like PVs. The provision of AS from wind turbines considering the FRT is discussed in [80]. The opportunity of FRT as an AS is also referred in [81], without elaborating details.

Furthermore, in the literature, many different methods have been proposed for clearing faults in distribution grids with high DG/DRES penetration. These methods can be classified into three main groups. The first group proposes the modification of the existing protective philosophy by applying alternative conventional protective methodologies. Such methodologies are the voltage-based protection [82], the distance protection [83], the differential protection [84,85] and the directional overcurrent protection [86]. The second group approaches this problem differently, trying to mitigate the adverse behavior of the DRES in case of short-circuit faults, as for example by applying fault current limiters $[87,88]$ and disconnecting the DRES $[89,90]$. The last group is composed by more advanced methodologies, which rely on communication technologies and adaptive systems. According to reference [91], the categories are: adaptive protection [92,93] differential protection [94] and artificial intelligence based algorithms [95]. In [96], an example of an islanded microgrid fed by volatile DRES and conventional overcurrent devices is presented by clearing faults with certain limitations.

An example illustrating the combined FRT and current injection by DRES for fault clearing is shown in Figure 5. In the first case, presented in Figure 5a, it is assumed that the upstream grid has sufficient short-circuit capacity. In this case, it would be preferable for all the DRES to inject zero current in order to avoid blinding of protection means R0 and R2. An extended FRT capability from the DRES is required and this can be achieved by incorporating a FSS at their DC-bus, which allows the suitable configuration of the FRT (adjustment of points 3 to 8 in Figure 5b). 


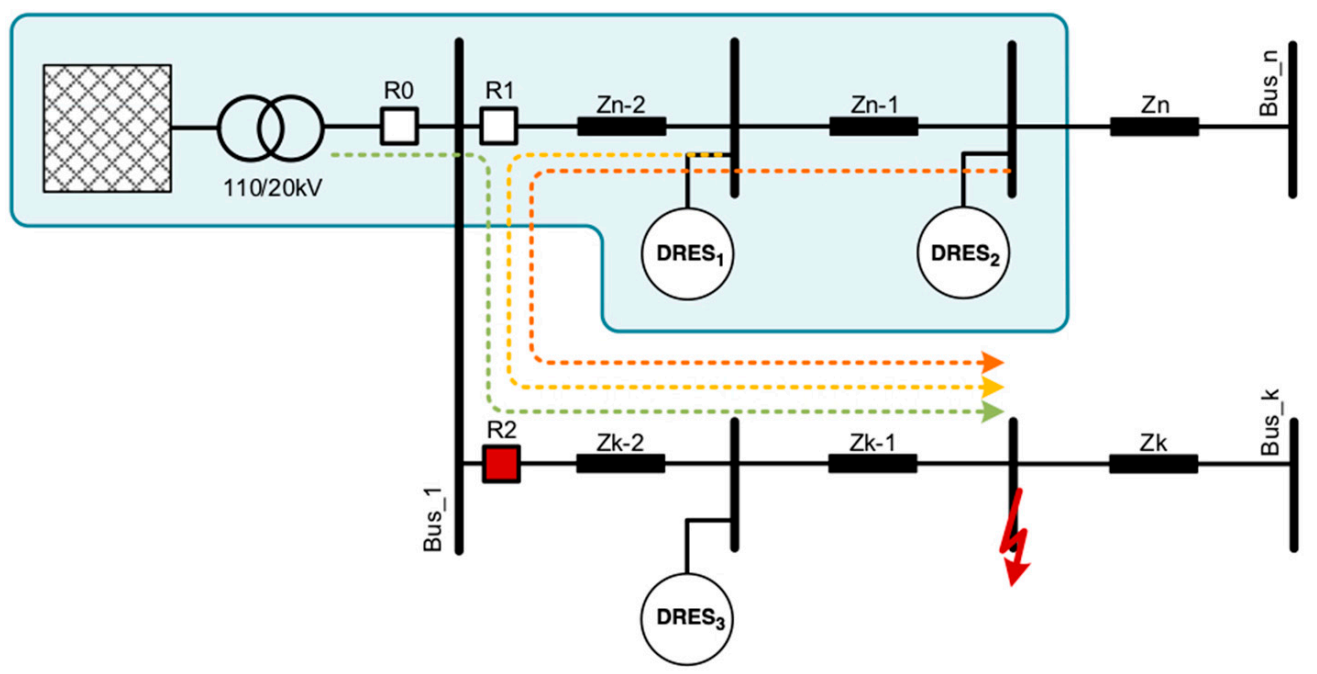

(a)

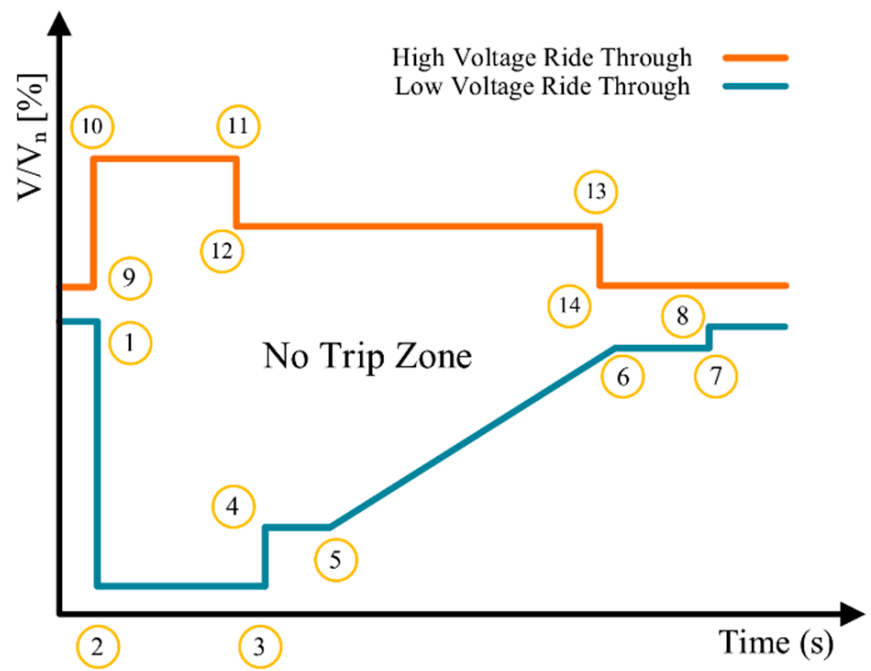

(b)

Figure 5. Illustrative example of DRES with FRT capability; (a) Possible cases for fault and DRES location in the two-feeder benchmark network; (b) generic FRT curve [97].

In the second case, the upstream grid is assumed to have insufficient short-circuit capacity for clearing the fault. In order to make R2 trip, $\mathrm{DRES}_{1}$ and $\mathrm{DRES}_{2}$ on the healthy feeder should contribute with controllable short-circuit currents, so that R1 does not trip (avoid sympathetic tripping), while $\mathrm{DRES}_{3}$ should not inject any current in order to limit the blinding of R2.

By following this approach, the existing protection means can be still functional, despite the increased DRES penetration. This means that investments on upgrade of protection system are deferred. However, new methods need to be developed so that the DRES can locally detect the location of the fault with respect to their position in the grid, i.e., whether the fault is upstream or downstream. Additionally, short-circuit analysis should be conducted regularly by the DSO in order to evaluate the short-circuit capability of the upstream grid and, thereafter, enable or disable the injection of current by the DRES or extend their FRT capability. Obviously, the extended FRT capability comes at an additional cost due to the required FSS system. However, the same FSS can be used for other AS, such as inertial response and ramp-rate control. Therefore, the allocation of the FSS into the various AS needs to be evaluated in the frame of future research. 


\subsubsection{Harmonics Mitigation}

The high proliferation of non-linear loads in the modern grids [98] together with the increasing penetration of converter-interfaced DRES [99] has resulted in a significant increase of the harmonic pollution in distribution networks. Furthermore, the harmonic pollution and the power quality in general can be considered as a factor for limiting the hosting capacity of a feeder [100]. In order to overcome this issue, the passive and active filtering of the feeders is proposed. Regarding the passive filtering, certain filters consisting of capacitors and inductors are proposed (such as C-type filters) $[101,102]$. Concerning the active filtering, several studies propose that the operation of the converter-interfaced DRES should also compensate the harmonics, both for three-phase (3-ph) and single-phase converters (1-ph). A detailed review of the active damping control methods appears in [103]. The harmonics mitigation could be remunerated as an AS. To enable this AS from the DG the existing grid codes that regulate the DG grid interconnection in the distribution system need to be modified. The IEEE Std. 1547-2018 [71] for DG grid connections, restrict the DG line current to meet the harmonics requirement without considering the distortion in voltage at the point of common coupling (PCC). Therefore, to improve the distribution system power quality, the DG will also attempt to control the distortion in system voltage and that leads to compensating harmonic current in the DG line currents. The new grid codes should be able to differentiate between these compensating currents. There should be relevant policies and markets for the financial compensation for DG, who participate in the AS [104].

\subsection{Suggested Procurement Schemes in Distribution Grids}

In this section, a brief description of the AS market from the distribution system level perspective is presented. Despite the fact that, according to the DSOs, currently no tradable AS is available in markets at distribution grid, suggestions and studies from the scientific literature are provided below.

\subsubsection{AS in Smart Grids and Microgrids}

The current increasing penetration of DRES in distribution networks impose new challenges in solving the emerging issues at local level. Furthermore, it should be taken into consideration the upcoming challenges of the DSO to carry out its own responsibilities, which include the development, operation and maintenance of the distribution grid in order to deliver high quality services to its final users. Therefore, the role of the DSO is strengthened, while the smartness of the distribution grid by the wide installation of smart metering infrastructure develops a new market environment evolving the future interaction between TSOs and DSOs. This urgent need is identified also in [105], while recent EN 50549-2019 Standards [61,62] regarding the connection of DRES at distribution system level have adopted the same specifications with the transmission system (EU Commission Regulation 2016/631 [24]), in aspects like active power response to over-frequency and under-frequency events, voltage support by reactive power, FRT and short-circuit current requirements.

Towards this direction, in [106], a top-to-bottom approach is analyzed, exploring the potential mechanisms for providing AS in the future smart grids. The proposed structure is based on developing time-varying electricity prices in order to manage the provision of AS for the entire grid. The importance of the role of DSO to the procurement of AS is also presented in [107], where the information and communication technologies for implementing the interaction among transmission and distribution grid is highlighted. In [18], the transition from hierarchical systems to open service-based smart systems based on agent technologies is investigated with emphasis to power quality. In [108], the multi-agent system electricity market for creating the role of an Aggregator is presented. The Aggregator will undertake the market representation of small and medium distributed resources for creating a competitive bidding strategy in energy and AS products. The opportunities of the demand side management and more specifically the interruptible load response on AS is provided in [109]. Through 
the development of the smart grids, the consumers will be able to respond to grid events by employing Interruptible Load Management (ILM) and Time-Of-Use (ToU) programs.

The concept of microgrids was firstly introduced in order to provide reliable solution to integration of DGs, ESS and controllable loads, while it can be regarded as a single controllable entity for the rest distribution grid [110,111]. The microgrids can operate both grid-connected supporting the utility grid operation and islanded in case of grid unavailability or fault. The control strategies of the involved DRES are mainly hierarchically distinguished in three levels: primary, secondary and tertiary, where each control level refers to different timeframe and operations, in a similar manner to the operation of conventional power systems. The primary and secondary control concern the internal operation of the microgrid, while the tertiary control focuses on the cooperation among microgrids. Therefore, the grid architecture can be divided into multiple microgrids, taking advantage of the smart grid infrastructure [112]. Through the development of new strategies in all control levels, the microgrid role in providing AS is investigated. Several AS have been addressed in the literature, either within the microgrid [113-115], or the allocation of AS among microgrids, [116] or the exchange of the AS between the microgrid and the main grid [117]. These AS are: frequency regulation [113,115], load following [113] and hourly active power ramping [113], fast reserve service, i.e., flexibility [114] (provided by dispatchable DRES), fast and transient exchange of reactive power [117], reactive power/voltage control, active loss balancing, and demand interruption [116]. In most cases the combination of both dispatchable (controllable) and non-dispatchable (uncontrollable) DRES is considered $[113,115]$.

\subsubsection{Integration of ESS and EVs for Providing AS}

A key element of the recent progress in smart grids and microgrids is the installation of ESS in order to support the stable operation of the distribution grids. However, the ESS can also be employed for providing AS to the distribution grids. These AS may include: voltage regulation $[118,119]$ taking into account sometime the network losses minimization [119] and congestion management [119], the provision of specific active and reactive power profile at the substation level [120], load changes, peak shaving, supporting the reactive power and compensating the power quality [73]. The ESS may be placed centrally at substation level [120], or may be combined with a converter-interfaced DG unit $[73,118,120]$. The study [120] considers both cases: the management of central and distributed ESS combined with DGs is assessed for remunerating the AS at distribution system level. The case of the ESS being private-owned or DSO-owned is considered for pursuing different economic strategies. Regarding the central ESS, the issue is to maintain the agreed power exchange profile, while the active power violation in case of combined distributed ESS at DG level is compared with the no-storage operation. Another kind of ESS for providing AS to the distribution grid is the EV, which is becoming attractive for numerous reasons, such as decreasing cost prices being competitive to the conventional fuel-based vehicle, new smart charging strategies, more ecological environmental footprint, etc. Many researchers have explored the opportunity of providing AS from the EV in the form of Vehicle-to-Grid $(\mathrm{V} 2 \mathrm{G})$ services. EVs are gaining popularity due to the fact that they are movable and distributed ESS that can be utilized in a coordinated way to provide flexibility.

In [121], the interaction of the EVs and the DRES is examined in order to provide AS to the distribution grid, such as voltage control and frequency regulation. As a result, the EVs can enhance the operational efficiency, secure the electric grid and reduce the operating costs of the power system. An optimization model for EVs in the smart grid content is presented in [122]. In this model, an optimization for a smart grid with a deferrable demand representing the charging of EVs is considered. A cost-benefit analysis is analytically examined, where the economic cost of production and the relevant costs regarding the demand shifting are regarded against the income deriving from the V2G services. In [123], the provision of AS (Peak Power Shaving, Voltage Regulation, Balancing mechanism, Primary frequency regulation, Load Management) from EVs is examined under the prism of the uncertainties of the EVs and the local limitations of the distribution grids. Several different bidding scenarios were 
considered examining the flexibility of the EVs for both the office and the home. The economic impact of the EVs for providing frequency regulation, spinning reserve, voltage support as AS are analysed in [124]. More specifically, a net present value (NPV) criteria is used for measuring the payback period of obtaining the capital and operational costs. Another point of view is provided in [125], where the competing objectives among the TSO and DSO are presented for the services of the EVs. Since new markets are arising, a common TSO-DSO AS market model is proposed as a solution for the conflicts of the AS among the two Operators. The AS are divided into "system-wide services", which include the primary, secondary and tertiary frequency regulation, the synthetic inertia and the adaptive charging, and the "distribution grid services", which are the MV/LV transformer and lines congestion management, LV over-/under-voltages management, LV grid phase balancing and islanded microgrid and black start.

\section{Market Tools and Mechanisms}

\subsection{Electricity Market at Distribution Grid Level}

Following the current market structure, the DRES are mainly connected in order to inject the available power to the grid, while the market operators remunerate their energy by applying several different pricing schemes (e.g., feed-in-tariff, feed-in-premium, net-metering, net-billing, etc.). However, according to reference [126], all DRES technologies have the potential to provide downward and upward adjustment to the systems. Therefore, they should be considered as a powerful tool for balancing the electricity networks. As it is previously analysed, the DRES can provide a diversity of services having an important economic footprint. In this manner, they can decrease the overall cost of the DSOs by enhancing the active distribution management concept, which is opposed to the traditional "fit-and-forget approach". Nevertheless, it is not easy for the TSOs and DSOs to procure the demanded flexibility services, since their coordination level should be enhanced [127].

According to more recent research, the interest is concentrated on providing AS from the distribution grid to System Operators by implementing a "bottom-up approach" [128]. This concept sounds more reasonable as the share of small DRES in the distribution grid is constantly increasing. Towards this perspective, in $[129,130]$, it is stated that the DSOs should develop their own local electricity markets, since the DSOs are considered as market neutral. Therefore, the DSOs will be able to support the TSOs' obligations by providing localized solutions. In [19], the following coordination schemes are proposed:

I. Centralized AS market model: there is a common market for resources connected both at distribution and transmission grid level, without any participation from the DSO.

II. Local AS market model: there is a local market operated by the DSO concerning the resources at distribution grid level. After the market closure, the DSO makes the proper aggregation in order to bid the remaining in AS market, operated by the TSO.

III. Shared balancing responsibility model: Each operator (DSO and TSO) operates separately at each network the balancing responsibilities. Therefore, there is a local market at DSO with a pre-agreed power exchange schedule with the TSO, while the resources at distribution grid cannot bid their offers directly to the TSO. The pre-agreed schedule can be determined by considering the results of the spot markets, which are defined as energy-only markets, or alternatively by using the past forecasts at each common point of connection between DSO-TSO.

IV. Common TSO-DSO AS market model: In this model, both operators (TSO and DSO) share the common target of decreasing the overall operational cost of the resources. This aim can be achieved by operate jointly a single market (namely central variant). Another approach proposes the dynamic integration of a decentralized DSO market (namely the local market) and a central TSO market (namely decentralized variant). 
Central variant: A single market session is operated, where all bids are offered and cleared considering both distribution and transmission constraints.

Decentralized variant: initially, a local market operated by the DSO for local needs takes place by considering the grid constraints at distribution grid level. Consequently, all local markets interact with the central TSO market.

V. Integrated flexibility market model: In the final market configuration, a more liberate market structure is proposed, where both Operators (TSOs, DSOs) and other market participants (such as balancing responsible parties) can participate in order to fulfil their needs. However, an unbiased market operator is needed for ensuring neutrality. Therefore, in this case, AS markets and intraday markets can difficulty be discretized.

From the presented models, different coordination schemes emerge at the distribution grid, changing the current philosophy for the procurement of AS in the electricity grids. Furthermore, the relationship between the TSO and DSO is advanced, while the distinction of their roles is becoming blurred in some cases. By comparing these models, a gradual expansion of the role of the DSO regarding the AS can be identified [19].

Another philosophy concerning emerging trading models is presented in [106]. Having as a goal the maximization of the social welfare, a peer-to-peer (P2P) model is proposed, avoiding any interference with the market operator. Instead of the current market structure, a community of agents is created in order to facilitate local energy trading. Each agent interacts and trades directly each other by employing an online platform based on the blockchain technology [131].

\subsection{Ideas for Incentives to DRESs for Participation in AS Markets}

A number of ideas have been presented in the scientific literature with respect to the ASs that can be offered by the DRESs and their remuneration. Initially, the current remuneration schemes for the DSOs themselves is questioned in references $[131,132]$ due to the high DRES penetration. The main reason is that, currently, DSOs are remunerated on the basis of energy flows which however change significantly under high DRES penetration. On the other hand, managing the instantaneous power becomes more important since it is the driving force behind, for example, feeder upgrades. The same is true for the maintenance and upgrade of protection systems as they are seriously affected by the DRES.

Next, the possible participation of the DRES in the AS markets already existing in the transmission system is investigated in [97,132-135], however focusing mainly on the flexibility (i.e., active power management) that the DRES can offer. For this reason, incentives stemming from dynamic pricing schemes are proposed. The complexity of such schemes and the resulting obstacles are also identified in $[97,134,135]$. The complexity is based on various factors such as (i) the different efficiency and availability among the DRES, e.g., non-dispatchable DRES (PV or wind) cannot offer the same AS or cannot be equally controlled as dispatchable ones (small hydro or biomass); (ii) the lack of transparency from the TSO point of view, since currently the TSOs are not aware of the DRES connected in the distribution grids and do not know their properties, thereby, their ability to offer AS; (iii) a coordinated control or the DRES is required in order to provide AS of significant amount, therefore, the control of the DRES should be taken over by another entity such as the DSO or aggregator; and (iv) the coordinated control of the DRES requires an extended ICT infrastructure which is currently absent from almost all distribution grids.

\section{Obstacles and Barriers}

This review paper outlines the introduction of novel ASs to the distribution system level along with the establishment of proper market schemes. However, several obstacles arise imposing the involved parties to act in a cooperative way in order to overcome them [127]. Network operators, electrical/electronic manufacturers, policy makers, and specialized economists are among those parties that will carry the burden of the transition to a more decentralized, but still stable and secure network 
environment. The aggregation of the aforementioned AS and their secure and controllable provision to the upstream TSO, still remains an open research issue. In reference [7], some recommendations are made with respect to the monitoring and Active System Management (ASM) through all voltage levels. Mostly the active power management, as a part of ASM is described and analyzed from the perspective of a close collaboration of TSOs and DSOs, for congestion management in both distribution and transmission grids and system balancing when such services are provided in a market-based approach by flexibilities owned and operated by third parties. In addition, reactive power management has been left out of the report. The reason to concentrate first on congestion management and balancing services provided by third parties is they have priority in the TSO-DSO coordination in order to ensure the security of supply. The urgent need for TSO-DSO co-operation to ensure efficient interaction with market parties is also identified and analyzed, and it is stressed out that DSOs and TSOs need a toolbox comprising different types of solutions for undertaking congestion management and balancing. These include (i) technical solutions using grid assets, (ii) tariff solutions, (iii) market-based solutions, and (iv) connection agreement solutions.

In this paper, a first categorization of further challenges to be addressed can be made between technical, regulatory and financial matters, which also suggests the most suitable parties that are going to lead the change in each case.

\subsection{Technical Barriers}

One of the most significant barriers is related to the current coordination level between the TSOs and the DSOs, which is regarded quite poor and cannot serve for the efficient provision of AS, taking into account their bottom-up approach. This is due to the following reasons: the first one is the fact that the numerous DRESs within the distribution systems are not "visible" and controllable by the TSOs. In this context, not even the DSOs know the dynamic capabilities of the DRESs within their own distribution grids, simply because this is not part of their business-at least, not until now. This situation is comprehensively presented in the recently published (April 2019) "TSO-DSO Report: An Integrated Approach to Active System Management" [7]. The second reason is the absence of methodologies to determine the aggregated response of a whole active distribution grid at the PCC with the transmission system for given response capabilities of the individual DRES. For example, let us assume that the inertial response of all DRES within a distribution system is known. How is the aggregated in inertial response calculated considering also technical constraints within the distribution grid? The reverse case is also still unexplored, i.e., the assignment of certain AS-response characteristics to specific DRES within a distribution grid, so that the overall response is the one requested by the TSO. The third reason, which is a direct consequence of the first two, is the absence of methods for developing simplified yet accurate equivalent electric models of the whole distribution grid for both dynamic and steady state condition as the DRES and load mixture changes. Such equivalent models would be the main communication means between TSO-DSO enabling the former to evaluate the response of the whole grid taking into account the contribution of DRESs connected in the distribution system, i.e., not controlled by the TSO. Generally, the TSO-DSO coordination is a matter of particular interest within the Horizon 2020 project "SmartNet", which further investigates the interaction schemes between TSOs and DSOs in order to facilitate the increasing DRES integration [132]. Another project dealing with the coordination between DSOs and TSOs in order to procure grid services in a reliable and efficient way is CoordiNET [11]. According to reference [136], the exchange of information between TSOs and DSOs is considered limited, which is a serious issue for bridging the gap among DSOs and TSOs. In the upcoming decentralized systems with DRES penetration, each operator should reconsider the role to the energy systems and especially to the AS market. In reference [137], it is proposed that the DSO will be in charge of collect the small-sized DRES and provide AS to the TSO in a coordinated manner. Another reason for the poor coordination between TSOs and DSOs regards the lack of establishment of a clear definition of the hierarchical procedures. To this end, common grid codes to distribution and transmission, with explicit focus on the cooperation is missing. Some solutions to this issue are 
proposed in reference [19], where the coordination schemes for developing different market structures is emerged, based on the communication principles among the operators. Furthermore, specific guidelines for building a strengthened coordination are included in the EDSO report [138]: the TSOs and DSOs should clearly define the data they need from each other, schedule the system planning, define the connection requirements for DRES and end-users, and develop coordinated networks codes.

A significant challenge is also the installation of a proper ICT infrastructure in order to exchange the necessary data for monitoring, accounting and control of the AS provided by distribution entities (e.g., DRES, flexible loads) to the transmission system [132,139]. Some barriers in this regard include the not-so-clear specifications for enabling security while transmitting data through existing communication standards. In [62], it is mentioned that standardized communication should be used for signal transmission between the DSO or TSO control centers and the DRES (e.g., EN 61850-7-4, EN 61850-7-420, IEC/TR 61850-90-7, as well as EN 61400-25 for wind turbines). In parallel, the standards need to consider the aspect of interoperability for various devices, operators, and services to exchange information in a seamless manner. As it can be deduced, since the aforementioned specifications are quite vague, the need for "visibility" [7] of each individual DRES up to the transmission system cannot be met.

Another technical obstacle is the lack of validated and commonly agreed methods for the quantification of services at distribution system level. It is noted a service should be quantified in order to become tradable in a market. The quantification should be made both at the terminals of each DRES and at the transmission-distribution interface when an AS is offered to the transmission system in aggregated form. A first attempt to define metrics for some AS has been already done in references $[51,97,133]$. Therefore, it is essential to establish new quantification methods that will reflect the actual provision of every service at the points of interest with relatively high accuracy. To this end, modern metering devices will also need to be installed being fully in line with the new measurement standards. The latter is emphasized in reference [105], as one of the technical challenges that the DSOs are facing due to the increasing share of DRES. The current measuring systems installed in most distribution networks do not serve for the DSOs to gain access over particular key quantities, necessary for enacting any control over DRES units, such as instructing a particular active power reduction or adjusting reactive power in order to maintain the system balance. Currently, the measuring devices used in distribution grids include SCADA systems, distribution line measurement systems and smart meters [134], and measure data related to the steady-state operation of the network [135]. As a result, they cannot capture and quantify AS related to the dynamic network operation (e.g., inertia or harmonic mitigation). Moreover, according to the requirements for the interconnection of DRES [71], their built-in metering infrastructure presents limited measurement capability with respect to dynamic phenomena, while they focus on the accurate detection of changes and not on the accurate calculation of absolute values [140]. Phasor Measurement Units (PMUs) [141] are mainly used at the transmission system acting on a fast timescale and can provide synchronized measurements. However, as it was proved difficult for the PMU manufacturers to comply with the strict limits [142], an amendment of the IEEE Standard C37.118.1 was published relaxing these limits, thus introducing inaccuracies under dynamic conditions [143].

Finally, the introduction of the new suggested AS imposes indirectly necessity in the update of the control strategies of the converter-interfaced DRES. Although recent standards and grid codes $[61,62,71,72]$ specify new functionalities for DRES (e.g., $P-f$ and $Q-V$ droops with variable slopes and settings) [24], the DSOs "lock" the operational mode of the DRES according to the currently applicable grid codes. For instance, in most of the cases the operation mode is "locked" into "MPP Tracking" mode because the DRES got a connection permission just for injecting renewable energy. Thus, other functionalities, such as the exchange of reactive power, or contribution to PFR are disabled. Therefore, an aggregator for instance, needs to request for permissions to "unlock" the full DRES capabilities, and of course, assume the full responsibility on their operation. 


\subsection{Regulatory Barriers}

Policy makers and regulatory authorities can have a major effect on the way ASs will be provided to the power system in case of increased DRES penetration, while they can certainly facilitate the establishment of an AS market at the distribution system level. However, until now, obstacles appear at the regulatory framework of most countries that discourage the establishment of new ASs and prevent the DRES operators from offering their services. This issue is particularly discussed in reference [144], which analyzes the future scenario of AS provision by DRES and Demand Response (DR) at the distribution level. More specifically, technology and size limitations imposed by the present regulations are referred to as one of the main reasons why DRES units and loads are excluded from the AS markets, even though they could potentially provide the requested services. Additionally, minimum bid size requirements are usually set for individual units and aggregation of services is forbidden in many countries, hence preventing small generating and load units from participating in the market. Finally, some ASs are defined for both upward and downward regulation, which raises an obstacle to some providers.

In reference [145], an overview of barriers that hinder the integration of PV units in the European distribution system is presented. Among others, the authors claim that the regulatory framework defining the network planning responsibilities of the DSOs does not promote smart grid investments. Although such investments are necessary for the development of AS markets at the distribution level, additional expenditures arise for the DSOs, which should be recovered by the establishment of a proper revenue scheme. Another obstacle emerges by the requirement of several regulations in Europe that PV units should continuously operate in their MPP, hence excluding their contribution to balancing, which results in increased costs for grid reinforcement. The absence of a particular policy and regulatory framework for PV units to provide AS is also described in reference [105], which outlines the issues of the DSOs due to increased DRES penetration. The necessity for the DSOs to define the active and reactive power output of individual DRES in emergency conditions is also emphasized, as currently there is no legal provision for them to gain access to the units' converters capabilities directly.

Another aspect highly investigated by the recent literature is the participation of BESS in the energy market along with their contribution to the AS provision within the distribution networks. Among others, [146] presents and analyzes the main regulatory barriers that hamper their deployment and prevent them from entering the electricity market, resulting in their poor participation in the AS market as well. The classification of BESS as a generation asset rather than a flexibility provider by the current regulation imposes double network usage charges to their owners, hence discourages their extensive usage. TSOs and DSOs are also restricted from owning and operating storage facilities, in compliance with the unbundling obligations of the EU Directive 2009/72/EC (despite being best positioned for their optimal use), which leads to significant uncertainty for further investments. Finally, the lack of proper balancing and AS markets that would facilitate the increased use of BESS technologies, in order to provide their valuable flexibilities to the system, is pointed out as one of the main barriers to their development. In reference [147], the authors recognize that the current perception of storage, as a supplementary asset to assist generation in balancing load, does not serve for the exploitation of its full potential in providing additional flexibility services. In particular, it is referred that the existing regulatory framework hinders the full development of ESSs, by setting limits to revenues coming from multiple market services, such as the AS market. This also stems from the fact that there is neither clearly defined storage-pricing policy nor specific tariff-regulation, until now. Therefore, it is proposed that effective regulatory and financial policies should be established, identifying storage as a distinct asset class, would it be for it to play a central role in the restructured electricity market.

Another barrier is the fact that the current market regulations treat the DSO mainly as market facilitator (or service requesting entity), leaving the offer of AS to third parties, like the aggregators. However, a number of technical constraints should be respected when offering ASs based on DRESs located within the distribution grid. Therefore, the DSO should be involved in the process of evaluating the technically feasible amount of each AS that can be offered at any time period, even in the cases an 
aggregator is responsible for the trading of these AS. This issue has to be considered in the modification of the respective AS market regulatory framework.

\subsection{Financial Barriers}

As more and more DRES are going to provide AS to both the distribution and the transmission system level, it is essential that a proper remuneration scheme is introduced, based on the value estimation of each service. According to reference [148], the electricity markets should be developed accordingly, so that the value of the flexible resources is more visible in market prices and proper investment signals are sent. Currently, non-dispatchable DRES providers are excluded from the AS market, since, as previously referred, there is no financial policy to incentivize them to offer their services. Furthermore, these DRES are mainly favored by alternative remuneration schemes, which are implemented in most countries and guarantee much more beneficial prices (e.g., feed-in-tarrifs, net-metering, net-billing, feed-in-premium, etc.). On the other hand, conventional generating units and some types of dispatchable RES (e.g., biogas, hydro) mostly offer their flexibility resources in long-term bilateral contracts between them and system operators, at fixed regulated prices. The necessity for a more realistic definition of the AS value, based on a proper estimation of the related installation costs and benefits is also underlined in reference [149], which proposes the development of efficient operational signals that should be sent via nodal energy prices, such as Distribution Locational Marginal Prices (DLMPs).

Another serious obstacle that prevents AS providers from offering their services, is relating to the timing of markets. According to reference [150], the current scheme does not provide for the market participants to react faster in the changing conditions caused by the intermittent generation. However, the recent European Commission regulations recognize their need to adjust the imbalances in the intraday market time-frame, as close to the real time as possible [3]. Therefore, a maximum time of one hour between intraday gate closure and real-time operation has been established, while a discussion is currently taking place between different National Regulatory Authorities (NRAs) in Europe in order to reduce the particular time window to half an hour.

Finally, following the aforementioned necessary investments regarding the ICT infrastructure and the measuring system that need to be installed at the transmission and the distribution level, an appropriate recovery scheme should be introduced so that the corresponding network operators can manage their costs. This is stressed in reference [7]. However, according to reference [145], the tendency of the current regulations to promote short-term cost reductions, especially for the DSOs, may not accommodate for this type of expenditures, leading to a climate of uncertainty for such investments.

\subsection{Potential Barriers Regarding the New Emerging ASs}

- Inertial response: The quantification of the inertial response faces a number of challenges. (i) Inertial response is actually detectable only in cases of large ROCOFs, i.e., under major frequency events. Thus, for most of the time, the inertial response results in power deviations of the DRESs' electrical power that are too small to be measured. On the other hand, inertial response is present all the time helping the system to arrest large frequency deviations. (ii) If we assume the realistic case where the various DRES within a distribution system have different inertia constants, the quantification of the aggregated inertial response, as seen at POI of the distribution-transmission system is still an open research issue. (iii) The term "inertial response" is currently used also for the action of FFR. Such a response is provided by DRES that are not associated with a fast ESS (e.g., supercapacitor or flywheel). Therefore, it is actually a late inertial response, for which the measurement of frequency and ROCOF is required. The latter, in turn, poses challenges with respect to the accurate quantification of this service.

- PFR: Until now, SG units are paid for their capacity offers and in some cases for the energy injected when providing the service [22]. A key challenge is highlighted in reference [151], which examines the participation of DRES in PFR by proposing a novel procedure to design the frequency droop 
curves, in an attempt that every distribution feeder provides a guaranteed frequency response at the feeder head (transmission-distribution interface). However, a concern arises regarding the contribution of every single unit to the service so that they are not unfairly penalized and inject the required power to the system based on their ratings and their location in the distribution network. If such behavior can be achieved, an additional solution should be found in terms of remunerating the aggregated service provided to the TSO and distributing the payments to the individual DRES/BESS providers. Those payments should be based on the power output of every unit, as indicated by a proper measuring system, in accordance to what was previously referred.

- Voltage regulation: Several technical problems during voltage regulation with reactive power are identified, such as (i) technical capability of providing the required reactive power characteristic; (ii) impedances of the DG plant components are not sufficiently considered during the planning operation of the DG; and (iii) the requested reactive power is provided at connection terminals of the DG units and not at PCC of the entire DG [150]. Therefore, apart for deriving a proper definition and metric for the reactive power, the reactive power capability of the converter-interfaced DRESs should also be properly evaluated. Also, this particular AS adds costs to converter-interfaced DRESs, due to the active power losses within the converter and the step-up transformers (whenever they exist), leading to a reduction in the overall efficiency [76]. These costs should be taken into account and compensated.

- Power smoothing/ramp-rate control: Currently, power smoothing is not recognized as an AS by most grid operators. However, in some cases of islanded and RES-heavy power systems, grid codes define maximum variability level of DRES, typically in terms of ramp rates, hence regard power smoothing as a system support function [152]. The development of this service highly depends on the deployment of ESS technologies. Therefore, any obstacle preventing their usage in order to provide additional flexibilities, especially within the distribution networks, can also be regarded as an obstacle for power smoothing. In reference [153], the installation and control of ESS for reducing the variability of PV units is considered to significantly raise to their operating cost as well as the cost of their produced power. Such costs can be recovered only if power smoothing is provided as an AS and a relevant market is introduced. Also, since mainly TSOs are going to take advantage of the service's benefits, because of the reduction in the number of units in reserve when power smoothing is provided, a relevant market needs to be introduced at the transmission system level, in parallel with the market for PFR procurement.

- $\quad$ FRT and fault clearing: An important challenge of the fault participation of DRES units regards the fault current limitation, which is imposed in most of the converter-interfaced DRES because of the thermal limits of the switching devices. Therefore, the use of the conventional over-current protection techniques cannot be facilitated [154]. Hence, the capability of the converter to provide fault-currents should be also evaluated. If converters are oversized to meet this demand, additional costs will arise for the producers that should be taken into account when providing the service. Finally, the benefit of making the DRES inject certain currents during the fault period so that the selectivity of the existing protection means is preserved even under very large DRES penetration should be accordingly evaluated.

- Harmonic mitigation: The idea for the injection of certain harmonic currents in order to mitigate the voltage harmonic pollution at specific nodes within the distribution system is not applicable until now, since several international standards establish particular harmonic current limits to the connecting facilities, as a way to mitigate voltage harmonics. This may be required either directly, as in the case of IEEE Std. 519-2014 [154,155] or indirectly, by setting voltage harmonic limits, which in combination with the system impedance lead to the respective current limits (e.g., IEC 61000-3-6 Std. [156]). It is evident from the review conducted in the previous section that harmonic mitigation by DRES is already considered in the literature as possible ASs. Therefore, the particular standards need to be revised in order to allow some of the DRESs to act like active 
harmonic filters. Finally, the additional cost incurred for making a DRES operate as an active filter is not yet addressed.

\section{Suggestions and Conclusions}

This paper provides a detailed review of ASs currently provided and remunerated in several countries across the world as well as a comprehensive review of the existing market regulations with respect to the AS provision at the transmission system level. Moreover, an in-depth review with respect to new ASs that can be provided by DRESs is carried out for both distribution and transmission system level. Figure 6 indicatively shows the AS dealt with in the EASY-RES project [157], together with the voltage level they are meant for. ICA stands for Independent Control Area, which is actually considered to be the distribution system.

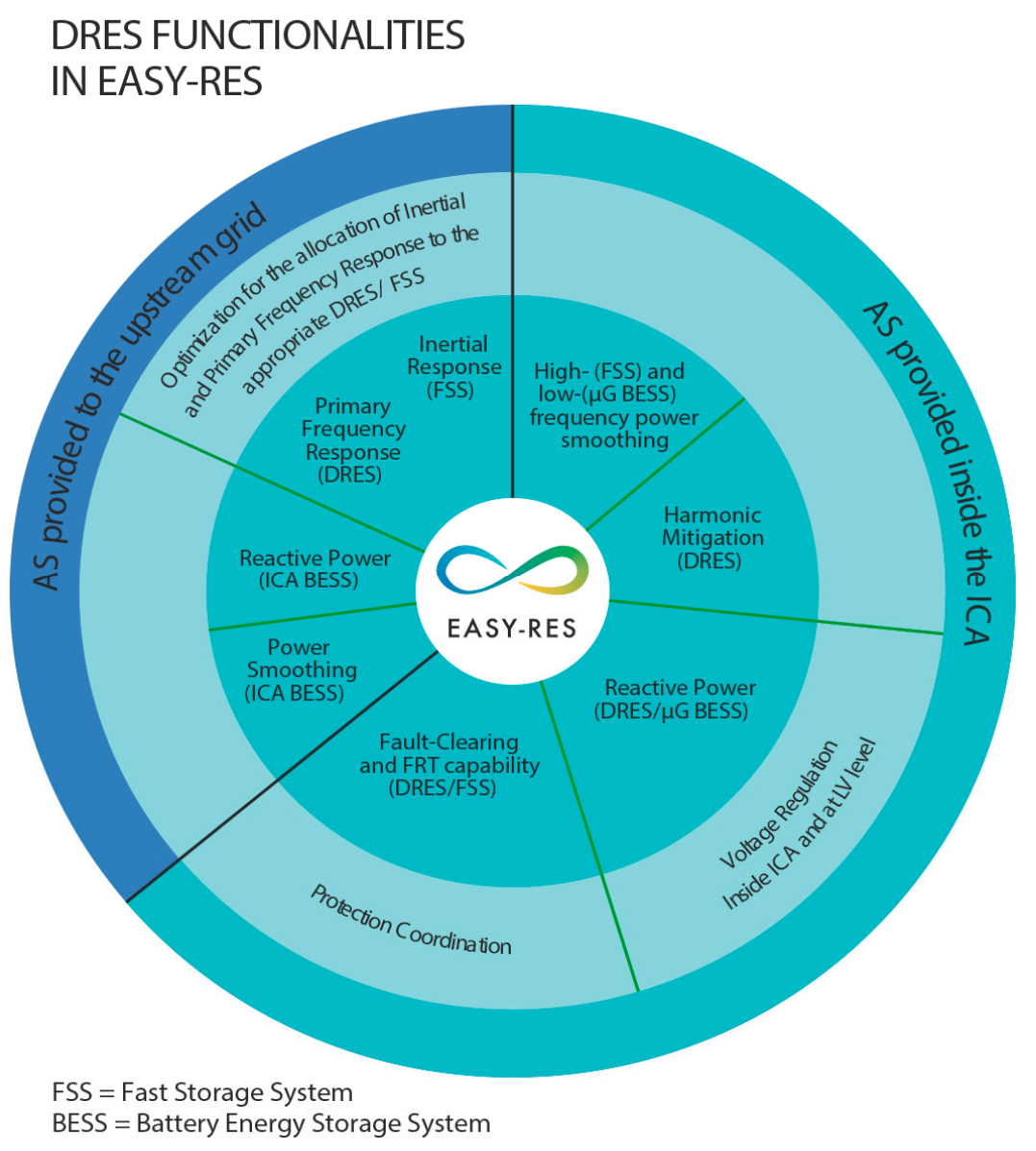

Figure 6. New ASs dealt with in the EASY-RES project [157].

These ASs are currently considered as system support functions that are mandatory for the DRES connection. A review of new market schemes with respect to AS remuneration at distribution system is conducted. Finally, the obstacles and barriers for the new ASs to be introduced in market schemes are identified. These obstacles are categorized as technical, regulatory and financial, while the barriers per each AS individually are also identified.

A general conclusion that can be drawn from the information presented in this paper is that ASs are currently provided only to the transmission system and mainly offered by large scale conventional units. However, the conventional units are gradually displaced by the increasing penetration of the DRES in the distribution system. It is well known that these DRESs, particularly those that converter-interfaced can provide a number of new functionalities which are currently considered 
as system-support functions. To transform the system-support functions into ASs, the following suggestions are presented:

Suggestion 1: Methods for the quantification of each service should be developed, validated and agreed among the interested stakeholders. The quantification should include specifications on the measurement approach and the associated accuracy. Moreover, in cases an AS is offered to the upstream transmission system (e.g., virtual inertia, PFR, reactive power support, ramp-rate control), measurements should be made in a synchronized manner on each DRES participating in the AS and on the POI with the transmission system in order to evaluate the actual amount of service that has been delivered at the POI and the contribution of each DRES to this. In this context, the measuring devices should be capable of capturing services offered under transient or dynamic conditions (e.g., inertial response, or dynamic reactive power support) and have access to measurement conducted within the DRES converters such as the tracked Maximum Power Point. The latter is necessary in order to verify that, for instance, a DRES is operating under an agreed headroom being, thereby, able to provide PFR in underfrequency events.

Suggestion 2: Methods need to be developed so that an aggregator is able to evaluate the aggregated amount of service that can be delivered to the POI based on the type, size and location of the DRESs within the distribution system under their responsibility. This is essential in order to be able to make offers of ASs to their respective markets. Methods for the reverse procedure need also to be developed: after an agreed amount of an AS with TSO, the aggregator needs to evaluate the optimum, with respect to cost, allocation of this service to the portfolio of DRESs he manages. The aforementioned methods should take into account a number of technical constraints imposed by the proper operation of the specific distribution grid. For this reason, these methods should be transparent to the DSO and the final amounts of service will be fixed after DSO approval.

Suggestion 3: For a number of ASs that are meant to be offered within the distribution system, such as contribution to fault-clearing and harmonic mitigation, the quantification methods need to define the starting and ending moments of each service. For instance, the start of a fault condition and its end, thereby its duration should be defined so that the contribution of a DRES with controllable currents can be quantified. The same is true for the harmonic mitigation ASs where the existence of background harmonic distortion should be evaluated and taken into consideration in the quantification process.

Suggestion 4: Apart from the development of measurement and quantification methods, the associated costs (investment and operational) for each AS need to be evaluated in order to enable the development of viable business models and, eventually, AS markets at distribution grid level. It is also noted that the provision of inertial response, falls in the same category despite the fact that it is offered to the transmission system. The reason is that currently inertial response is still considered as a system-support function also at that voltage level because it is inherently provided by the conventional SGs. Therefore, no additional cost is implied. However, when inertia is provided synthetically, additional investment and operation costs emerge and need to be remunerated.

Suggestion 5: A rather simple but highly secure ICT system is required for the coordinated control of the various DRES within the distribution grid and the accounting of the quantified ASs. The ICT can be simple since most of the ASs are based on the local control of the DRES converter while the role of the ICT is mainly the enabling/disabling of an AS in a DRES and the transmission of various set points in relatively large time intervals (of the order of minutes). Security is required because the measured ASs will be traded in an AS market and finally remunerated. For the same reason, the ICT system and the control and accounting platforms should be transparent and accessible to all involved stakeholders. The cost associated with the development, operation and maintenance of such an ICT system should be considered in the development of business models together with the aforementioned costs of the DRESs.

Suggestion 6: A registry containing all the properties of the DRESs within a distribution system should be made and be transparent to the TSO [7]. This will form the basis for further development of methods for the estimation of the equivalent models (containing both the steady-state and dynamic 
behavior) of the distribution grid considering the technical constraints within it. The transparent registry and topology of the distribution grid will help in the validation and mutual acceptance of the equivalent models enabling the TSO to use them in the evaluation of the whole system response treating the distribution grids as VPPs. The equivalent models need to be regularly (every 5-10 min) updated to reflect the changing DRES penetration and load variation [157].

To sum up, the main highlights of this review are listed below:

- The DRES within the distribution grids can provide a number of traditional and new AS, thus enabling the decommitment of conventional SG, mostly driven by fossil fuels while maintaining the secure and stable operation of the power system.

- A number of obstacles and barriers need to be overcome for the introduction of AS originating from the DRESs. First, a number of technical and economic issues need to be researched as mentioned in the four suggestions above, particularly the measurement and quantification of the new services so that they cease to be treated as system-support functions and start to be treated as tradable ASs.

- Each of the aforementioned suggestions presents a research topic that involves, apart from researchers, regulatory authorities, and standardization bodies.

- The list of the ASs presented in Figure 6 is not exhaustive but simply presents those ASs treated in the EASY-RES project. Additional services may be defined (for instance, congestion management) which however need to be properly delimited in order to be treated as future ASs.

Author Contributions: K.O. is the main author and conducted the main review of ancillary services at transmission and distribution grid level, mainly regarding the microgrid operation, protection and frequency control. K.-N.M. conducted extensive review research regarding the ancillary services at transmission and distribution grid level and especially regarding the voltage control. K.G., A.T. and C.D. (Christos Dikaiakos) are members of Research, Technology \& Development Department at Independent Power Transmission Operator (IPTO) in Greece. They provided data regarding the ancillary services at transmission system and also conducted a literature review regarding the provision of ancillary services at EU and non-EU countries. S.G. conducted extensive review research regarding the ancillary services at transmission and distribution grid level and especially regarding the fault protection and the operation of wind-driven generators. M.C. provided research data regarding the operation of converter-based RES and their capability to provide ancillary services. J.M.M., J.M.M.O. and J.L.M.R. conducted review on inertia ancillary service at distribution grid level. G.P. conducted research about the ancillary services that they are currently traded by TSOs in EU countries, identification of the issues at the transmission systems in case of high Distributed Renewable Energy Sources penetration and the respective cooperation between the Transmission System Operator (TSO) and the Distribution System Operator (DSO). C.D. (Charis Demoulias) conducted thorough review regarding the operation of the distribution grid with high penetration of distributed RES and their capability to provide ancillary services to the grid Operators. All authors also participate in EASY-RES EU funded project, which deals with the integration of ancillary services from distributed RES at distribution grid level. All authors have read and agreed to the published version of the manuscript.

Funding: This research is part of the EASY-RES project that has received funding from the European Union's Horizon 2020 Research and Innovation program under Grant Agreement No. 764090.

Conflicts of Interest: The authors declare no conflict of interest. The funders had no role in the design of the study; in the collection, analyses, or interpretation of data; in the writing of the manuscript, or in the decision to publish the results. 


\section{Appendix A}

Table A1. Frequency reserves in various EU countries.

\begin{tabular}{|c|c|c|c|c|}
\hline Country & FCR & aFRR & mFRR & $\mathbf{R R}$ \\
\hline Austria & $\begin{array}{c}\text { Generators/Load/Pump Storage/Batteries } \\
\leq 1 \mathrm{MW}\end{array}$ & $\begin{array}{c}1 \mathrm{MW}<\text { Generators/Load/Pump Storage } \\
\leq 5 \mathrm{MW}\end{array}$ & Generators/Load/Pump Storage $\leq 1 \mathrm{MW}$ & No \\
\hline Belgium & Generators/Load/Pump Storage $\leq 1 \mathrm{MW}$ & Generators/Load/Pump Storage $\leq 1 \mathrm{MW}$ & Generators/Load/Pump Storage $\leq 1 \mathrm{MW}$ & No \\
\hline Bosnia and Herzegovina & Generators only (no minimum) & $1 \mathrm{MW}<$ Generators only $\leq 5 \mathrm{MW}$ & $5 \mathrm{MW}<$ Generators/Load $\leq 10 \mathrm{MW}$ & No \\
\hline Croatia & Generators only (no minimum) & Generators only $\leq 1 \mathrm{MW}$ & Generators/Pump Storage $\leq 1 \mathrm{MW}$ & No \\
\hline Czechia & $1 \mathrm{MW}<$ Generators only $\leq 5 \mathrm{MW}$ & $1 \mathrm{MW}<$ Generators/Load $\leq 5 \mathrm{MW}$ & $\begin{array}{c}1 \mathrm{MW}<\text { Generators/Load/Pump Storage } \\
\leq 5 \mathrm{MW}\end{array}$ & No \\
\hline Denmark & Generators/Load/Batteries $\leq 1 \mathrm{MW}$ & $1 \mathrm{MW}<$ Generators/Load $\leq 5 \mathrm{MW}$ & $5 \mathrm{MW}<$ Generators/Load $\leq 10 \mathrm{MW}$ & No \\
\hline Estonia & - & No & - & - \\
\hline Finland & Generators/Load/Batteries $\leq 1 \mathrm{MW}$ & $1 \mathrm{MW}<$ Generators only $\leq 5 \mathrm{MW}$ & $1 \mathrm{MW}<$ Generators/Load $\leq 5 \mathrm{MW}$ & No \\
\hline France & $\begin{array}{c}\text { Generators/Load/Pump Storage/Batteries } \\
\leq 1 \mathrm{MW}\end{array}$ & Generators/Pump Storage $\leq 1 \mathrm{MW}$ & $\begin{array}{c}5 \mathrm{MW}<\text { Generators/Load/Pump Storage } \\
\quad \leq 10 \mathrm{MW}\end{array}$ & $\begin{array}{c}5 \mathrm{MW}<\text { Generators/Load/Pump } \\
\text { Storage } \leq 10 \mathrm{MW}\end{array}$ \\
\hline Germany & $\begin{array}{c}1 \mathrm{MW}<\text { Generators/Load/Pump } \\
\text { Storage/Batteries } \leq 1 \mathrm{MW}\end{array}$ & $\begin{aligned} 1 \mathrm{MW} & <\text { Generators/Load/Pump Storage } \\
& \leq 5 \mathrm{MW}(90 \mathrm{~s}<\mathrm{t} \leq 5 \mathrm{~min})\end{aligned}$ & $\begin{aligned} 1 \mathrm{MW} & <\text { Generators/Load/Pump Storage } \\
& \leq 5 \mathrm{MW}(5 \mathrm{~min}<\mathrm{t} \leq 15 \mathrm{~min})\end{aligned}$ & No \\
\hline Great Britain & $\begin{array}{c}\text { Generators/Load/Pump Storage/Batteries } \\
\leq 5 \mathrm{MW}\end{array}$ & No & $\begin{array}{c}5 \mathrm{MW}<\text { Generators/Load/Pump } \\
\text { Storage/Batteries } \leq 10 \mathrm{MW}\end{array}$ & $\begin{array}{c}1 \mathrm{MW}<\text { Generators/Load/Pump } \\
\text { Storage } \leq 5 \mathrm{MW}\end{array}$ \\
\hline Greece & Generator only $\leq 1 \mathrm{MW}$ & Generators only $\leq 1 \mathrm{MW}$ & Generators only & No \\
\hline Hungary & Generators only $\leq 1 \mathrm{MW}$ & Generators only $\leq 1 \mathrm{MW}$ & No & Generators/Load $\leq 1 \mathrm{MW}$ \\
\hline Ireland & $\begin{array}{c}1 \mathrm{MW}<\text { Generators/Load/Pump } \\
\text { Storage/Batteries } \leq 5 \mathrm{MW}\end{array}$ & No & Generators/Load/Pump Storage $\leq 1 \mathrm{MW}$ & No \\
\hline Italy & (no minimum) & - & No & - \\
\hline Latvia & - & No & Generators only $\leq 1 \mathrm{MW}$ & No \\
\hline Lithuania & - & No & Generators/Pump Storage (no minimum) & $\begin{array}{c}\text { Generators/Load/Pump Storage } \\
\leq 1 \mathrm{MW}\end{array}$ \\
\hline
\end{tabular}


Table A1. Cont.

\begin{tabular}{|c|c|c|c|c|}
\hline Country & FCR & aFRR & mFRR & RR \\
\hline Netherlands & $\begin{array}{c}1 \mathrm{MW}<\text { Generators/Load/Batteries } \leq \\
5 \mathrm{MW}\end{array}$ & $\begin{array}{c}1 \mathrm{MW}<\text { Generators/Load/Batteries } \leq \\
5 \mathrm{MW}(\mathrm{t} \leq 90 \mathrm{~s})\end{array}$ & $5 \mathrm{MW}<$ Generators/Load $\leq 10 \mathrm{MW}$ & No \\
\hline Norway & Generators only $\leq 1 \mathrm{MW}$ & $5 \mathrm{MW}<$ Generators only $\leq 10 \mathrm{MW}$ & Generators/Load $\leq 1 \mathrm{MW}$ & No \\
\hline Poland & Generators only $\leq 1 \mathrm{MW}$ & Generators only $\leq 1 \mathrm{MW}$ & No & - \\
\hline Portugal & Generators only (no minimum) & $\begin{array}{c}\text { Generators only }>10 \mathrm{MW}(90 \mathrm{~s}<\mathrm{t} \leq \\
5 \mathrm{~min})\end{array}$ & $>10 \mathrm{MW}$ & $\leq 1 \mathrm{MW}$ \\
\hline Romania & $1 \mathrm{MW}<$ Generators only $\leq 5 \mathrm{MW}$ & Generators only $>10 \mathrm{MW}$ & $1 \mathrm{MW}<$ Generators only $\leq 5 \mathrm{MW}$ & $\begin{array}{c}1 \mathrm{MW}<\text { Generators only } \leq \\
5 \mathrm{MW}\end{array}$ \\
\hline Serbia & $1 \mathrm{MW}<$ Generators only $\leq 5 \mathrm{MW}$ & Generators only $\leq 1 \mathrm{MW}$ & Generators/Pump Storage $\leq 1 \mathrm{MW}$ & No \\
\hline Slovakia & Generators only $\leq 1 \mathrm{MW}$ & $1 \mathrm{MW}<$ Generators only $\leq 5 \mathrm{MW}$ & $\begin{array}{c}1 \mathrm{MW}<\text { Generators/Load/Pump Storage } \\
\leq 5 \mathrm{MW}\end{array}$ & No \\
\hline Slovenia & Generators only (no minimum) & $\begin{array}{c}\text { Generators/Pump Storage } \leq 1 \mathrm{MW} \text { (5 min } \\
<\mathrm{t} \leq 15 \mathrm{~min})\end{array}$ & $\begin{array}{c}\text { Generators/Load/Pump Storage } \leq 1 \mathrm{MW} \\
(5 \mathrm{~min}<\mathrm{t} \leq 15 \mathrm{~min})\end{array}$ & No \\
\hline Spain & Generators only (no minimum) & $\begin{array}{c}\text { Generators only }>10 \mathrm{MW}(90 \mathrm{~s}<\mathrm{t} \leq \\
5 \mathrm{~min})\end{array}$ & $\begin{array}{c}\text { Generators/Pump storage }>10 \mathrm{MW} \\
\quad(5 \mathrm{~min}<\mathrm{t} \leq 15 \mathrm{~min})\end{array}$ & $\begin{array}{l}\text { Generators/Pump Storage }> \\
10 \mathrm{MW}(20 \mathrm{~min}<\mathrm{t} \leq 1 \mathrm{~h})\end{array}$ \\
\hline Sweden & Generators only $\leq 1 \mathrm{MW}$ & $1 \mathrm{MW}<$ Generators only $\leq 5 \mathrm{MW}$ & $5 \mathrm{MW}<$ Generators/Load $\leq 10 \mathrm{MW}$ & No \\
\hline Switzerland & $\begin{array}{c}\text { Generators/Load/Pump Storage/Batteries } \\
\leq 1 \mathrm{MW}\end{array}$ & $\begin{array}{c}1 \mathrm{MW}<\text { Generators/Load/Pump } \\
\text { Storage/Batteries } \leq 5 \mathrm{MW}\end{array}$ & $\begin{array}{c}1 \mathrm{MW}<\text { Generators/Load/Pump } \\
\text { Storage/Batteries } \leq 5 \mathrm{MW}\end{array}$ & $\begin{array}{c}1 \mathrm{MW}<\text { Generators/Load/Pump } \\
\text { Storage/Batteries } \leq 5 \mathrm{MW}\end{array}$ \\
\hline
\end{tabular}


Table A2. Voltage control in various EU countries.

\begin{tabular}{|c|c|c|c|c|}
\hline Country & Mandatory & Providers & Voltage Level & Paid \\
\hline Austria & $\begin{array}{l}\text { Mandatory for power plants in } \\
\text { transmission system }\end{array}$ & $\begin{array}{l}\text { Generators/DSO/Wind } \\
\text { farms/DSO connected } \\
\text { units/Transformers }\end{array}$ & Transmission/Distribution & Partly \\
\hline Belgium & $\begin{array}{c}\text { No mandatory. All Generating units > } 25 \text { MVA } \\
\text { must be capable of voltage control }\end{array}$ & $\begin{array}{l}\text { Generators/Wind } \\
\text { farms/Transformers }\end{array}$ & Transmission & Yes \\
\hline Bosnia and Herzegovina & Mandatory & Generators & Transmission & No \\
\hline Croatia & All power plants & $\begin{array}{l}\text { Generators/Wind } \\
\text { farms/Transformers }\end{array}$ & Transmission/Distribution & Yes \\
\hline Czechia & All units connected at $220 \mathrm{kV}+$ & Generators/Transformers & Transmission & Yes \\
\hline Denmark & - & Generators/HVDC/Transformers & Transmission & Partly \\
\hline Estonia & $\begin{array}{l}\text { Mandatory for all plants connected to the main } \\
\text { grid }\end{array}$ & $\begin{array}{c}\text { Generators/Wind } \\
\text { farms/HVDC/Transformers }\end{array}$ & Transmission/Distribution & - \\
\hline Finland & Mandatory for all power plants & $\begin{array}{l}\text { Generators/Wind farms/DSO } \\
\text { connected units/Transformers }\end{array}$ & Transmission/Distribution & No \\
\hline France & $\begin{array}{l}\text { Mandatory primary voltage control for all units at } \\
\text { transmission level and secondary voltage } \\
\text { regulation for all units connected at }>225 \mathrm{kV}\end{array}$ & $\begin{array}{l}\text { Generators/Wind } \\
\text { farms/PV/HVDC }\end{array}$ & Transmission/Distribution & Partly \\
\hline Germany & $\begin{array}{l}\text { Voltage control requirements for plants in both } \\
\text { high- and medium-voltage }\end{array}$ & $\begin{array}{l}\text { Generators/Wind } \\
\text { farms/HVDC/DSO connected } \\
\text { units/Transformers }\end{array}$ & Transmission/Distribution & Partly \\
\hline Great Britain & $\begin{array}{l}\text { Mandatory for all conventional generators and } \\
\text { wind farms connected to transmission. }\end{array}$ & Generators/Transformers & Transmission/Distribution & Yes \\
\hline Greece & $\begin{array}{c}\text { Production units (except RES) }>2 \text { MW (comply } \\
\text { with technical regulation) }\end{array}$ & Generators/Transformers & Transmission & No \\
\hline Hungary & $\begin{array}{l}\text { All power plants }>50 \mathrm{MW} \text { connected to } \\
\text { transmission grid or } 132 \mathrm{kV}\end{array}$ & Generators/Transformers & Transmission/Distribution & Yes \\
\hline Ireland & - & Generators & - & - \\
\hline
\end{tabular}


Table A2. Cont.

\begin{tabular}{|c|c|c|c|c|}
\hline Country & Mandatory & Providers & Voltage Level & Paid \\
\hline Italy & Mandatory for power units $\geq 10 \mathrm{MVA}$ & Generators/Transformers & Transmission & No \\
\hline Latvia & Power plants & Generators/ Wind farms/Transformers & Transmission & No \\
\hline Lithuania & All power plants in transmission & $\begin{array}{c}\text { Generators/ Wind } \\
\text { farms/HVDC/Transformers }\end{array}$ & - & Partly \\
\hline Netherlands & $\begin{array}{l}\text { Mandatory for generators }>5 \mathrm{MW} \text {. It is a } \\
\text { contracted service }\end{array}$ & $\begin{array}{c}\text { Generators/DSO/Industrial } \\
\text { consumers/Wind farms/PV/HVDC/DSO } \\
\text { connected units/Transformers }\end{array}$ & Transmission/Distribution & Partly \\
\hline Norway & All powerplants & $\begin{array}{c}\text { Generators/DSO/Industrial } \\
\text { consumers/Wind farms/HVDC/DSO } \\
\text { connected units/Transformers }\end{array}$ & Transmission/Distribution & Yes \\
\hline Poland & $\begin{array}{l}\text { All Generating Units and also centrally dispatched } \\
\text { units contracted for this service }\end{array}$ & $\begin{array}{c}\text { Generators/ Wind farms/DSO connected } \\
\text { units/Transformers }\end{array}$ & Transmission/Distribution & Yes \\
\hline Portugal & All conventional generators & Generators & Transmission & No \\
\hline Romania & - & Generators & Transmission & No \\
\hline Serbia & $\begin{array}{l}\text { Mandatory for all power plants in } \\
\text { transmission grid }\end{array}$ & Generators/Transformers & Transmission & Yes \\
\hline Slovakia & $\begin{array}{c}\text { Mandatory primary voltage control, secondary } \\
\text { voltage control as a paid service at transmission } \\
\text { level }(400 \mathrm{kV} \text { and } 220 \mathrm{kV})\end{array}$ & Generators/Transformers & Transmission & Yes \\
\hline Slovenia & Yes, mandatory & Generators/Transformers & Transmission & Yes \\
\hline Spain & $\begin{array}{c}\text { Mandatory service for all power plants }>30 \mathrm{MW} \\
\text { connected to the transmission grid }\end{array}$ & $\begin{array}{c}\text { Generators/DSO/Industrial } \\
\text { consumers/Wind farms/PV/HVDC/DSO } \\
\text { connected units/Transformers }\end{array}$ & Transmission/Distribution & No \\
\hline Sweden & - & Generators/DSO & Transmission/Distribution & No \\
\hline Switzerland & $\begin{array}{c}\text { All power plants connected to transmission grid } \\
\text { with available reactive power and without } \\
\text { compromising the active power }\end{array}$ & Generators/DSO/Transformers & Transmission/Distribution & Yes \\
\hline
\end{tabular}


Table A3. Provision of black-start in various EU countries.

\begin{tabular}{|c|c|c|c|c|}
\hline Country & Mandatory & Voltage Level & Paid by TSO & $\begin{array}{l}\text { Regulated Gradient for } \\
\text { the BS Unit }\end{array}$ \\
\hline Austria & Hydro storage power plants. Not mandatory for power plants & Transmission & Yes & No \\
\hline Belgium & $\begin{array}{l}\text { Not mandatory, provided from gas power plant and } \\
\text { pumped storage. }\end{array}$ & Transmission & Yes & No \\
\hline Bosnia and Herzegovina & Mandatory & Transmission & No & - \\
\hline Croatia & Mandatory for plants determined by defense plan & Transmission/Distribution & & No \\
\hline Czechia & No obligations to provide black start from any unit & Transmission & Yes & - \\
\hline Denmark & Not mandatory & Transmission & Yes & $101 \mathrm{MW}-200 \mathrm{MW} / 15 \mathrm{~min}$ \\
\hline Estonia & $\begin{array}{l}\text { Not mandatory, provided by power plants included in } \\
\text { restoration plan }\end{array}$ & Transmission & Yes & - \\
\hline Finland & Not mandatory, agreed bilaterally by grid code. & Transmission/Distribution & Yes & No \\
\hline France & Not mandatory, provided by nuclear plants & Transmission/Distribution & No & - \\
\hline Germany & Specific contracts. & Transmission & Yes & No \\
\hline Great Britain & $\begin{array}{l}\text { Now mandatory. Procured via bilateral contracts with } \\
\text { power stations. }\end{array}$ & Transmission/Distribution & Yes & No \\
\hline Greece & By predefined power plants & Transmission & Yes & - \\
\hline Hungary & $\begin{array}{c}\text { Mandatory for power plants }>500 \mathrm{MW} \text { connected to } \\
\text { transmission grid. Also provided by other plants with } \\
\text { BS capability }\end{array}$ & Transmission/Distribution & Yes & No \\
\hline Ireland & $\begin{array}{c}\text { Mandatory for Northern Ireland for certain plant types } \\
\text { (Hydro, Pump storage, interconnectors, open cycle } \\
\text { gas turbines) }\end{array}$ & - & - & - \\
\hline Italy & Mandatory for power plants defined in restoration plan & Transmission & No & - \\
\hline Latvia & Agreements with hydro power plants & Transmission & Yes & No \\
\hline Lithuania & Not mandatory & Transmission & Yes & - \\
\hline Netherlands & Not mandatory, it is a contracted service & Transmission/Distribution & Yes & - \\
\hline
\end{tabular}


Table A3. Cont.

\begin{tabular}{|c|c|c|c|c|}
\hline Country & Mandatory & Voltage Level & Paid by TSO & $\begin{array}{l}\text { Regulated Gradient for } \\
\text { the BS Unit }\end{array}$ \\
\hline Norway & $\begin{array}{l}\text { Mandatory for power plants with significant impact on } \\
\text { reconstruction of network or other critical functions }\end{array}$ & Transmission/Distribution & No & No \\
\hline Poland & Not mandatory & - & Yes & No \\
\hline Portugal & Not mandatory, provided by a CCGT ${ }^{1}$ and a hydro plant & Transmission & Yes & No \\
\hline Romania & Mandatory for power plants included in black start plan & Transmission & No & No \\
\hline Serbia & Mandatory for Hydro Power Plants & Transmission & Yes & No \\
\hline Slovakia & Not mandatory & - & Yes & No \\
\hline Slovenia & Mandatory & Transmission & Yes & - \\
\hline Spain & Not mandatory, mainly provided by hydro plants & - & No & No \\
\hline Sweden & Contracts with suppliers & Transmission & Yes & - \\
\hline Switzerland & $\begin{array}{l}\text { ensure that for the reestablishment of supply after a major } \\
\text { incident an adequate number of power stations, qualified for } \\
\text { black start and island operation consolidated to a } \\
\text { buildup-cell }{ }^{2} \text {, are ready for operation }\end{array}$ & Transmission & Yes & No \\
\hline \multicolumn{5}{|c|}{${ }^{1}$ CCGT $=$ Combined Cycle Gas Turbine } \\
\hline \multicolumn{5}{|c|}{$\begin{array}{l}2 \text { A buildup-cell is defined as a small subnet, limited in area and electrical network, which consists of one power station equipped with black start facilities and one or more } \\
\text { power stations with islanding functionality being able to keep frequency, voltage and power stable in this buildup-cell, with an adequate load at its disposal. } \\
\text { The buildup-cell needs: } \\
\text {-to have a direct connection to the } 220 \mathrm{kV} \text {-level } \\
\text {-to be connected to the same or neighboring nodes } \\
\text {-Its rotating mass (power output) to be between } 200 \text { and } 250 \mathrm{MW} \text { and a switchable load of } 10 \%\end{array}$} \\
\hline
\end{tabular}


Table A4. Summary of AS and their procurement in several non-EU countries.

\begin{tabular}{|c|c|c|c|c|c|}
\hline \multirow[t]{2}{*}{ Country } & \multicolumn{3}{|c|}{ Frequency Control } & \multirow{2}{*}{$\begin{array}{c}\text { Voltage Management } \\
\text { Reactive power } \\
\text { absorbption/injection }\end{array}$} & \multirow{2}{*}{$\begin{array}{c}\text { Black Start } \\
\text { Restart the power system } \\
\text { after a black-out }\end{array}$} \\
\hline & Primary frequency control & Secondary frequency control & Tertiary frequency control & & \\
\hline \multirow{2}{*}{$\begin{array}{l}\text { California } \\
\text { (USA) }\end{array}$} & $\begin{array}{l}\text { Description: Not mandatory } \\
\text { service. The beneficiaries are } \\
\text { decided through a } \\
\text { competitive market }\end{array}$ & $\begin{array}{l}\text { Description: Must be } \\
\text { available in a } 10 \text { min window } \\
\text { and must be maintained for } \\
\text { a minimum of } 2 \mathrm{~h} .\end{array}$ & $\begin{array}{l}\text { Description: It can be } \\
\text { synchronous tertiary } \\
\text { frequency regulation or } \\
\text { non-synchronized reserve }\end{array}$ & $\begin{array}{l}\text { Description: Provided by all } \\
\text { Generators with PF between } \\
0.90 \text { and } 0.95 \text {. }\end{array}$ & $\begin{array}{l}\text { Description: CAISO jointly } \\
\text { with Participating } \\
\text { Transmission Owner analyse } \\
\text { the fulfillment of reliability in } \\
\text { order to define the quantity } \\
\text { and location of Generation } \\
\text { units need to provide } \\
\text { black-start }\end{array}$ \\
\hline & $\begin{array}{l}\text { Procurement of necessary } \\
\text { volume of service for each } \\
\text { control area as a percentage of } \\
\text { the total predicted load. } \\
\text { Typical values: } 5-12 \% \text { of the } \\
\text { demand. }\end{array}$ & $\begin{array}{l}\text { Procurement: Similar to } \\
\text { primary frequency. Typical } \\
\text { value: } 3 \% \text { of the maximum } \\
\text { demand }\end{array}$ & - & $\begin{array}{l}\text { Procurement of additional } \\
\text { reactive power needed } \\
\text { through bilateral agreements, } \\
\text { based on real-time needs. The } \\
\text { remuneration reflects the } \\
\text { opportunity cost of the } \\
\text { production lost depending on } \\
\text { capacity and use. }\end{array}$ & $\begin{array}{l}\text { Procurement: Generating } \\
\text { units can propose a bilateral } \\
\text { agreement to CAISO } \\
\text { (normally for a year) for } \\
\text { compensating the costs plus } \\
\text { additional benefits }\end{array}$ \\
\hline \multirow{2}{*}{ Argentina } & $\begin{array}{l}\text { Description: Response time } \\
\text { varies depending on the } \\
\text { technology (e.g., thermal } \\
\text { generators up to } 30 \mathrm{~s} \text {, hydro } \\
\text { up to } 60 \mathrm{~s} \text { ). The service should } \\
\text { be provided for about } 10 \text { min. }\end{array}$ & $\begin{array}{l}\text { Description: A generating } \\
\text { unit should have a ramping } \\
\text { capability of more than } \\
30 \mathrm{MW} / \mathrm{min} \text {. Response time } \\
\text { should be } 10-15 \text { min, none } \\
\text { specification for the total } \\
\text { duration. }\end{array}$ & - & $\begin{array}{l}\text { Description: The capacity of } \\
\text { required reactive power is } \\
\text { calculated by TSO. An } \\
\text { instantaneous response and } \\
\text { permanent supply of up to } \\
90 \% \text { of this reactive power for } \\
20 \text { min must be feasible. }\end{array}$ & $\begin{array}{l}\text { Description: After a partial or } \\
\text { total system collapse, each } \\
\text { operator sets a range of } \\
\text { actions that must be respected } \\
\text { by some users }\end{array}$ \\
\hline & $\begin{array}{l}\text { Procurement: Mandatory } \\
\text { service for all system } \\
\text { generators, who are } \\
\text { responsible to maintain the } \\
\text { frequency in their dispatched } \\
\text { area. They are not } \\
\text { compensated for this service. }\end{array}$ & $\begin{array}{l}\text { Procurement: Voluntary } \\
\text { service. In case of Hyrdo, the } \\
\text { system recognizes the cost of } \\
\text { the service provided as the } \\
\text { energy price that they offer, } \\
\text { while in thermal generator is } \\
\text { this payment is proportional } \\
\text { to the hydro price. }\end{array}$ & - & $\begin{array}{l}\text { Procurement: Provided by } \\
\text { generators and transmission } \\
\text { companies. Penalties to } \\
\text { generators, distributors and } \\
\text { large consumers for no } \\
\text { keeping their PF under the } \\
\text { regulated range. }\end{array}$ & $\begin{array}{l}\text { Procurement: Mandatory } \\
\text { service, but not specific } \\
\text { requirements for response } \\
\text { time, duration or } \\
\text { compensation schemes. }\end{array}$ \\
\hline
\end{tabular}


Table A4. Cont.

\begin{tabular}{|c|c|c|c|c|c|}
\hline Country & & Frequency Control & & Voltage Management & Black Start \\
\hline \multirow[t]{2}{*}{ New Zealand } & $\begin{array}{l}\text { Description: Instantaneous } \\
\text { reserve is generating capacity, } \\
\text { or interruptible load, } \\
\text { available to operate } \\
\text { automatically. This service is } \\
\text { required to stop the resulting } \\
\text { fall in frequency. } \\
\text { Over-frequency reserve is } \\
\text { provided by generating units } \\
\text { that can be armed when } \\
\text { required and automatically } \\
\text { disconnected from the power } \\
\text { system due to a sudden rise } \\
\text { in system frequency. Back-up } \\
\text { Single Frequency Keeping } \\
\text { (Back-Up SFK) }\end{array}$ & $\begin{array}{l}\text { Description: Multiple } \\
\text { Frequency Keeping. This } \\
\text { service is provided by one or } \\
\text { more generators capable of } \\
\text { quickly varying their output } \\
\text { in response to instructions } \\
\text { from the System Operator. } \\
\text { Back-up single frequency. } \\
\text { Only takes effect if the system } \\
\text { operator cannot deliver } \\
\text { multiple frequency keeping. }\end{array}$ & - & $\begin{array}{l}\text { Description: Voltage support } \\
\text { is provided by generating } \\
\text { units or static equipment } \\
\text { capable of producing or } \\
\text { absorbing reactive power }\end{array}$ & $\begin{array}{l}\text { Description: Process of } \\
\text { system restoration in the } \\
\text { unlikely event of an } \\
\text { island-wide black-out }\end{array}$ \\
\hline & $\begin{array}{c}\text { Procurement: Instantaneous } \\
\text { reserve, } 30 \text { min clearing } \\
\text { market. } \\
\text { Over-frequency reserve, } \\
\text { bilateral contracts. Back-Up } \\
\text { SFK: monthly availability fee }\end{array}$ & $\begin{array}{l}\text { Procurement: Multiple } \\
\text { Frequency Keeping } 30 \text { min } \\
\text { clearing market } \\
\text { Back-up Single frequency. } \\
\text { Bilateral contracts with } \\
\text { tendering process }\end{array}$ & - & $\begin{array}{l}\text { Procurement: Voltage support } \\
\text { is procured on a firm quantity } \\
\text { procurement basis (via a } \\
\text { monthly availability fee } \\
\text { and/or a single event fee for a } \\
\text { specified MVAr availability). }\end{array}$ & $\begin{array}{l}\text { Procurement: Bilateral } \\
\text { contracts with tendering } \\
\text { process }\end{array}$ \\
\hline
\end{tabular}


Table A4. Cont.

\begin{tabular}{|c|c|c|c|c|c|}
\hline Country & & Frequency Control & & Voltage Management & Black Start \\
\hline \multirow[t]{2}{*}{ Australia } & $\begin{array}{l}\text { Description: Primary } \\
\text { frequency control is designed } \\
\text { to act within several seconds } \\
\text { (and generally up to } \\
\text { approximately } 60 \mathrm{~s} \text { ) to } \\
\text { provide a proportional } \\
\text { response to measured } \\
\text { changes in local frequency } \\
\text { and contain deviations. }\end{array}$ & $\begin{array}{l}\text { Description: Increase or } \\
\text { reduction of active power, in } \\
\text { response to a remote signal, to } \\
\text { restore the system's frequency } \\
\text { back to } 50 \mathrm{~Hz} \text {. }\end{array}$ & $\begin{array}{l}\text { Description: Because the } \\
\text { NEM has a relatively } \\
\text { short dispatch interval of } \\
\text { five minutes, tertiary } \\
\text { frequency control, which } \\
\text { acts to relieve sources of } \\
\text { primary and secondary } \\
\text { frequency control, is } \\
\text { effectively achieved } \\
\text { through the central } \\
\text { dispatch process which } \\
\text { re-balances the system } \\
\text { every five minutes. }\end{array}$ & $\begin{array}{l}\text { Description: AEMO operates } \\
\text { the power system to keep } \\
\text { voltage level across } \\
\text { connection points in the } \\
\text { transmission network within } \\
\text { a target range. This involves } \\
\text { the coordination of available } \\
\text { reactive power reserves } \\
\text { provided by the network } \\
\text { assets and generating units. } \\
\text { (Reactive power supply. PF } \\
\text { between } 0.9 \text { inductive and } \\
0.93 \text { capacitive) }\end{array}$ & $\begin{array}{l}\text { Description: Provided in case } \\
\text { of contingency, after a major } \\
\text { supply disruption or when } \\
\text { power system restart is } \\
\text { required. }\end{array}$ \\
\hline & $\begin{array}{l}\text { Procurement: Fast and slow } \\
\text { contingency frequency } \\
\text { control ancillary services } \\
\text { (FCAS) Markets. Competitive } \\
\text { auctions. Capacity and use. }\end{array}$ & $\begin{array}{l}\text { Procurement: Managed in the } \\
\text { NEM through the use of } \\
\text { regulation and delayed } \\
\text { contingency FCAS services. } \\
\text { Competitive auctions. } \\
\text { Real-time dispatch. }\end{array}$ & $\begin{array}{l}\text { Procurement: } \\
\text { Competitive auctions. } \\
\text { Real-time dispatch. }\end{array}$ & $\begin{array}{l}\text { Procurement: Bilateral } \\
\text { Contracts }\end{array}$ & $\begin{array}{l}\text { Procurement: Bilateral } \\
\text { contracts on each zone of the } \\
\text { power system. The service is } \\
\text { paid on the basis of } \\
\text { availability. }\end{array}$ \\
\hline
\end{tabular}




\section{References}

1. Strasser, T.; Andrén, F.; Kathan, J.; Cecati, C.; Buccella, C.; Siano, P.; Leitão, P.; Zhabelova, G.; Vyatkin, V.; Vrba, P.; et al. A Review of Architectures and Concepts for Intelligence in Future Electric Energy Systems. IEEE Trans. Ind. Electron. 2015, 62, 2424-2438. [CrossRef]

2. Pirbazari, A.M. Ancillary services definitions, markets and practices in the world. In 2010 IEEE/PES Transmission and Distribution Conference and Exposition; Latin America (T\&D-LA): Sao Paulo, Brazil, 2010; pp. 32-36.

3. European Commission (EU). Commission Regulation (EU) 2015/1222 of 24 July 2015 Establishing A Guideline on Capacity Allocation and Congestion Management. Available online: https://eur-lex.europa.eu/legalcontent/EN/TXT/PDF/?uri=CELEX:32016R0631\&from=EN (accessed on 30 December 2019).

4. Commission Regulation (EU). Commission Regulation (EU) 2016/1388 of 17 August 2016 Establishing a Network Code on Demand Connection. Available online: https://eur-lex.europa.eu/legal-content/EN/TXT/ PDF/?uri=CELEX:32016R1388\&from $=$ EN (accessed on 30 December 2019).

5. Holttinen, H.; Cutululis, N.A.; Gubina, A.; Keane, A.; Van Hulle, F. Ancillary Services: Technical Specifications, System Needs and Costs. Deliverable D 2.2. Available online: http://orbit.dtu.dk/files/72251308/Ancillary_ Services.pdf (accessed on 30 December 2019).

6. Kaushal, A.; Van Hertem, D. An Overview of Ancillary Services and HVDC Systems in European Context. Energies 2019, 12, 3481. [CrossRef]

7. ENTSO-E, E.DSO, Eurelectric, GEODE \& CEDEC. TSO-DSO REPORT: An Integrated Approach to Active System Management with the Focus on TSO-DSO Coordination in Congestion Management and Balancing. Available online: https:/docstore.entsoe.eu/Documents/Publications/Position\%20papers\%20and\%20reports/ TSO-DSO_ASM_2019_190416.pdf (accessed on 30 December 2019).

8. Zhao, X.; Chang, L.; Shao, R.; Spence, K. Power system support functions provided by smart inverters-A review. CPSS Trans. Power Electron. Appl. 2018, 3, 25-35. [CrossRef]

9. Gallos, K.; Tsitsimelis, A.; Dikaiakos, C.; Mushtaq, U.; Cvetkovic, M.; Vargas, A.A.; Mauricio, J.M.; Santos, J.R.; Maza, J.M.; Demoulias, C.; et al. D5.1 Report Reviewing the Current Market Regulatory Framework. Available online: https://cordis.europa.eu/project/rcn/213757/results/en (accessed on 30 December 2019).

10. Cabrera-Tobar, A.; Bullich-Massagué, E.; Aragüés-Peñalba, M.; Gomis-Bellmunt, O. Review of advanced grid requirements for the integration of large scale photovoltaic power plants in the transmission system. Renew. Sustain. Energy Rev. 2016, 62, 971-987. [CrossRef]

11. Heard, B.P.; Brook, B.W.; Wigley, T.M.L.; Bradshaw, C.J.A. Burden of proof: A comprehensive review of the feasibility of $100 \%$ renewable-electricity systems. Renew. Sustain. Energy Rev. 2017, 76, 1122-1133. [CrossRef]

12. Eid, C.; Codani, P.; Perez, Y.; Reneses, J.; Hakvoort, R. Managing electric flexibility from Distributed Energy Resources: A review of incentives for market design. Renew. Sustain. Energy Rev. 2016, 64, $237-247$. [CrossRef]

13. Attya, A.B.; Dominguez-Garcia, J.L.; Anaya-Lara, O. A review on frequency support provision by wind power plants: Current and future challenges. Renew. Sustain. Energy Rev. 2018, 81, 2071-2087. [CrossRef]

14. Karbouj, H.; Rather, Z.H.; Flynn, D.; Qazi, H.W. Non-synchronous fast frequency reserves in renewable energy integrated power systems: A critical review. Int. J. Electr. Power Energy Syst. 2019, 106, 488-501. [CrossRef]

15. Rebours, Y.G.; Kirschen, D.S.; Trotignon, M.; Rossignol, S. A Survey of Frequency and Voltage Control Ancillary Services-Part I: Technical Features. IEEE Trans. Power Syst. 2007, 22, 350-357. [CrossRef]

16. Rebours, Y.G.; Kirschen, D.S.; Trotignon, M.; Rossignol, S. A Survey of Frequency and Voltage Control Ancillary Services-Part II: Economic Features. IEEE Trans. Power Syst. 2007, 22, 358-366. [CrossRef]

17. Newbery, D.; Pollitt, M.G.; Ritz, R.A.; Strielkowski, W. Market design for a high-renewables European electricity system. Renew. Sustain. Energy Rev. 2018, 91, 695-707. [CrossRef]

18. Gustavsson, R.; Hussain, S.; Saleem, A. Ancillary services for smart grids-Power quality markets. In Proceedings of the 2013 IEEE Grenoble Conference, Grenoble, France, 16-20 June 2013; pp. 1-6.

19. Gerard, H.; Rivero Puente, E.I.; Six, D. Coordination between transmission and distribution system operators in the electricity sector: A conceptual framework. Util. Policy 2018, 50, 40-48. [CrossRef] 
20. National Renewable Energy (NREL). An Introduction to Grid Services: Concepts, Technical Requirements, and Provision from Wind. Available online: https://www.nrel.gov/docs/fy19osti/73590.pdf (accessed on 30 December 2019).

21. Daniel, S.; Kirschen, G.S. Fundamentals of Power System Economics, 2nd ed.; WILEY: Hoboken, NJ, USA, 2018.

22. ENTSO-E WGAS. Survey on Ancillary Services Procurement, Balancing Market Design 2017. Available online: https:/docstore.entsoe.eu/Documents/Publications/Market\%20Committee\%20publications/ENTSOE_AS_survey_2017.pdf (accessed on 30 December 2019).

23. ENTSO-E. Parameters Related to Voltage Issues, ENTSO-E Guidance Document for National Implementation for Network Codes on Grid Connection. Available online: https://docstore.entsoe.eu/Documents/Network\% 20codes\%20documents/NC\%20RfG/161116_IGD_Parameters\%20related\%20to\%20voltage\%20issues_for\% 20publication.pdf (accessed on 30 December 2019).

24. Regulation (EU). Commission Regulation (EU) 2016/631 of 14 April 2016 Establishing a Network Code on Requirements for Grid Connection of Generators; Commission. Available online: https:/eur-lex.europa.eu/ legal-content/EN/TXT/PDF/?uri=CELEX:32016R0631\&from=EN (accessed on 30 December 2019).

25. Gevorgian, V.; Booth, S.; National Renewable Energy Laboratory. Review of PREPA Technical Requirements for Interconnecting Wind and Solar Generation. 2013. Available online: https:/www.nrel.gov/docs/fy14osti/ 57089.pdf (accessed on 30 December 2019).

26. Karapidakis, E.S.; Tsikalakis, A.G.; Katsigiannis, Y.A.; Moschakis, M. Impact of Increased RES Generation on Power Systems Dynamic Performance. Mater. Sci. Forum 2012, 721, 185-190. [CrossRef]

27. Miller, N.W.; Clark, K.; Shao, M. Frequency responsive wind plant controls: Impacts on grid performance. In Proceedings of the 2011 IEEE Power and Energy Society General Meeting, Detroit, MI, USA, $24-29$ July 2011; pp. 1-8.

28. Ulbig, A.; Borsche, T.S.; Andersson, G. Analyzing Rotational Inertia, Grid Topology and their Role for Power System Stability. IFAC-PapersOnLine 2015, 48, 541-547. [CrossRef]

29. Yan, R.; Saha, T.K. Frequency response estimation method for high wind penetration considering wind turbine frequency support functions. IET Renew. Power Gener. 2015, 9, 775-782. [CrossRef]

30. Fairley, P. Can Synthetic Inertia from Wind Power Stabilize Grids? IEEE Spectr. 2016. Available online: https: //spectrum.ieee.org/energywise/energy/renewables/can-synthetic-inertia-stabilize-power-grids (accessed on 30 December 2019).

31. Voges, R. Synthetic Inertia from Wind Turbine Generation. Gen. Electr. 2017. Available online: https://www.mro.net/MRODocuments/Synthetic\%20Inertia\%20from\%20Wind\%20Turbine\%20Generation, \%20Randy\%20Voges.pdf (accessed on 30 December 2019).

32. Brisebois, J.; Aubut, N. Wind farm inertia emulation to fulfill Hydro-Québec's specific need. In Proceedings of the 2011 IEEE Power and Energy Society General Meeting, Detroit, MI, USA, 24-29 July 2011; pp. 1-7.

33. Ela, E.; Kirby, B.; Navid, N.; Smith, J. Effective Ancillary Services Market Designs on High Wind Power Penetration Systems. In Proceedings of the IEEE Power and Energy Society General Meeting, San Diego, CA, USA, 22-26 July 2012; pp. 1-8.

34. D'Arco, S.; Suul, J.A.; Fosso, O.B. A Virtual Synchronous Machine implementation for distributed control of power converters in SmartGrids. Electr. Power Syst. Res. 2015, 122, 180-197. [CrossRef]

35. Bevrani, H.; Ise, T.; Miura, Y. Virtual synchronous generators: A survey and new perspectives. Int. J. Electr. Power Energy Syst. 2014, 54, 244-254. [CrossRef]

36. Tamrakar, U.; Shrestha, D.; Maharjan, M.; Bhattarai, B.; Hansen, T.; Tonkoski, R. Virtual Inertia: Current Trends and Future Directions. Appl. Sci. 2017, 7, 654. [CrossRef]

37. Tan, S.; Geng, H.; Yang, G.; Wang, H.; Blaabjerg, F. Modeling framework of voltage-source converters based on equivalence with synchronous generator. J. Mod. Power Syst. Clean Energy 2018, 6, 1291-1305. [CrossRef]

38. Thiesen, H.; Jauch, C.; Gloe, A. Design of a System Substituting Today's Inherent Inertia in the European Continental Synchronous Area. Energies 2016, 9, 582. [CrossRef]

39. Luna, A.; Tamrakar, U.; Hansen, T.M.; Tonkoski, R. Frequency Response in Grids with High Penetration of Renewable Energy Sources. In Proceedings of the 2018 North American Power Symposium (NAPS), Fargo, ND, USA, 9-11 September 2018; pp. 1-5. 
40. ENTSO-E. ENTSO-E Guidance Document for National Implementation for Network Codes on Grid Connection: Need for Synthetic Inertia (SI) for Frequency Regulation. Available online: https://docstore.entsoe.eu/Documents/Network\%20codes\%20documents/NC\%20RfG/IGD_Need_for_ Synthetic_Inertia_final.pdf (accessed on 30 December 2019).

41. Agranat, O.; Macgill, I.; Bruce, A. Fast Frequency Markets under High Penetrations of Renewable Energy in the Australian National Electricity Market. In Proceedings of the Asia Pacific Solar Research Conference, Queensland, Australia, 8-10 December 2015.

42. Xu, T.; Jang, W.; Overbye, T. An Economic Evaluation Tool of Inertia Services for Systems with Integrated Wind Power and Fast-Acting Storage Resources. In Proceedings of the 2016 49th Hawaii International Conference on System Sciences (HICSS), Koloa, HI, USA, 5-8 January 2016; pp. 2456-2465.

43. Sanduleac, M.; Chimirel, C.; Toma, L.; Alacreu, L.; Pons, L. National and inter-TSO balancing and ancillary services markets within a pyramid of energy services. In Proceedings of the Mediterranean Conference on Power Generation, Transmission, Distribution and Energy Conversion (MedPower 2016), Belgrade, Serbia, 6-9 November 2016; pp. 1-6.

44. Ireland. System Services: Portfolio Capability Analysis. EirGrid Group and System Operator of Northern. Available online: http:/www.eirgridgroup.com/site-files/library/EirGrid/System-Services-ConsultationNew-Products-and-Contractual-Arrangements-June_2012.pdf (accessed on 30 December 2019).

45. Denholm, P.; O'Connell, M.; Brinkman, G.; Jorgenson, J. Overgeneration from Solar Energy in California. In A Field Guide to the Duck Chart; National Renewable Energy Lab.(NREL): Golden, CO, USA, 2015. Available online: https://www.osti.gov/servlets/purl/1226167 (accessed on 30 December 2019).

46. Kirby, B.; Milligan, M. An Examination of Capacity and Ramping Impacts of Wind Energy on Power Systems. Electr. J. 2008, 21, 30-42.

47. Crăciun, B.; Kerekes, T.; Séra, D.; Teodorescu, R.; Annakkage, U.D. Power Ramp Limitation Capabilities of Large PV Power Plants With Active Power Reserves. IEEE Trans. Sustain. Energy 2017, 8, 573-581. [CrossRef]

48. EirGrid. WFPS-Active-Power-Control-Test-Procedure. Available online: http://www.eirgridgroup.com/ library/index.xml (accessed on 30 December 2019).

49. Puerto Rico Public Private Partnerships Authority. Request for Qualifications for the Puerto Rico Electric Power Authority Utility Scale Energy Storage System Project. Available online: http://www.p3.pr.gov/assets/ rfq-energy-project-june-2018.pdf (accessed on 30 December 2019).

50. Zhang, Y.; Duan, Z.; Liu, X. Comparison of Grid Code Requirements with Wind Turbine in China and Europe. In Proceedings of the 2010 Asia-Pacific Power and Energy Engineering Conference, Chengdu, China, 28-31 March 2010; pp. 1-4.

51. Malamaki, K.-N.; Gkavanoudis, S.; Mushtaq, U.; Cvetkovic, M.; Marano, A.; Gallos, K.; Dikaiakos, C.; Jerele, M.; Schneider, C.; Damböck, R. D1.1 Description of the Metrics Developed for The Quasi-Steady-State Operation and Report on The Review of The Respective Current Grid Codes. Available online: https: //cordis.europa.eu/project/rcn/213757/results/en (accessed on 30 December 2019).

52. Gkavanoudis, S.I.; Demoulias, C.S. A combined fault ride-through and power smoothing control method for full-converter wind turbines employing Supercapacitor Energy Storage System. Electr. Power Syst. Res. 2014, 106, 62-72. [CrossRef]

53. Pegueroles-Queralt, J.; Bianchi, F.D.; Gomis-Bellmunt, O. A Power Smoothing System Based on Supercapacitors for Renewable Distributed Generation. IEEE Trans. Ind. Electron. 2015, 62, 343-350. [CrossRef]

54. Li, X.; Hui, D.; Lai, X. Battery Energy Storage Station (BESS)-Based Smoothing Control of Photovoltaic (PV) and Wind Power Generation Fluctuations. IEEE Trans. Sustain. Energy 2013, 4, 464-473. [CrossRef]

55. Saiz-Marin, E.; Garcia-Gonzalez, J.; Barquin, J.; Lobato, E. Economic Assessment of the Participation of Wind Generation in the Secondary Regulation Market. IEEE Trans. Power Syst. 2012, 27, 866-874. [CrossRef]

56. Kirby, B.M.M.; Ela, E. Providing Minute-To-Minute Regulation from Wind Plants. In Proceedings of the 9th Annual International Workshop on Large-Scale Integration of Wind Power into Power Systems and Transmission Networks for Offshore Wind Power Plants, Québec, QC, Canada, 18-19 October 2010.

57. Ela, E.; Gevorgian, V.; Fleming, P.; Zhang, Y.C.; Singh, M.; Muljadi, E.; Scholbrook, A.; Aho, J.; Buckspan, A.; Pao, L.; et al. Active Power Controls from Wind Power: Bridging the Gaps. Available online: https: //www.osti.gov/servlets/purl/1117060 (accessed on 30 December 2019). 
58. Ocker, F.; Ehrhart, K.-M. The "German Paradox" in the balancing power markets. Renew. Sustain. Energy Rev. 2017, 67, 892-898. [CrossRef]

59. Gevorgian, V.; Zhang, Y.; Ela, E. Investigating the Impacts of Wind Generation Participation in Interconnection Frequency Response. IEEE Trans. Sustain. Energy 2015, 6, 1004-1012. [CrossRef]

60. Ingleson, J.W.; Allen, E. Tracking the Eastern Interconnection frequency governing characteristic. In Proceedings of the IEEE PES General Meeting, Providence, RI, USA, 25-29 July 2010; pp. 1-6.

61. EN50549-1:2019 Requirements for Generating Plants to be Connected in Parallel with Distribution Networks-Part 1: Connection to a LV Distribution Network- Generating Plants up to and Including Type B; European Committee for Electrotechnical Standardization (CENELEC): Brussels, Belgium, 2019.

62. EN50549-2:2019 Requirements for Generating Plants to Be Connected in Parallel with Distribution Networks-Part 2: Connection to a MV Distribution Network-Generating Plants Up to and Including Type B; European Committee for Electrotechnical Standardization (CENELEC): Brussels, Belgium, 2019.

63. KU Leuven Energy Institute. The Current Electricity Market Design in Europe. Available online: https: //set.kuleuven.be (accessed on 30 December 2019).

64. ENTSO-E. System Operations Guideline 2017. Available online: https://www.entsoe.eu/network_codes/sysops/ (accessed on 30 December 2019).

65. Karbouj, H.; Rather, Z.H. Voltage Control Ancillary Service From Wind Power Plant. IEEE Trans. Sustain. Energy 2019, 10, 759-767. [CrossRef]

66. Tennet TSO GmbH. Grid Code: High and Extra High Voltage. Available online: https://www. tennet.eu/electricity-market/german-customers/grid-customers/grid-connection-regulations/ (accessed on 30 December 2019).

67. EirGrid. EirGrid Grid Code. Available online: http://www.eirgridgroup.com/site-files/library/EirGrid/ GridCodeVersion6.pdf (accessed on 30 December 2019).

68. EirGrid Group and System Operator of Northern Ireland. Ensuring a Secure, Reliable and Efficient Power System in a Changing Environment. Available online: http://www.eirgridgroup.com/site-files/library/EirGrid/ Ensuring-a-Secure-Reliable-and-Efficient-Power-System-Report.pdf (accessed on 30 December 2019).

69. Carvalho, P.M.S.; Correia, P.F.; Ferreira, L.A.F.M. Distributed Reactive Power Generation Control for Voltage Rise Mitigation in Distribution Networks. IEEE Trans. Power Syst. 2008, 23, 766-772. [CrossRef]

70. Herman, L.; Blažič, B.; Papič, I. Voltage profile support in LV distribution networks with distributed generation. In Proceedings of the 2009 44th International Universities Power Engineering Conference (UPEC), Glasgow, UK, 1-4 September 2009; pp. 1-5.

71. IEEE Standard for Interconnection and Interoperability of Distributed Energy Resources with Associated Electric Power Systems Interfaces. In IEEE Std 1547-2018 (Revision of IEEE Std 1547-2003); IEEE: Piscataway, NJ, USA, 2018; pp. 1-138.

72. Technische und organisatorische Regeln für Betreiber und Benutzer von Netzen, Teil D: Besondere technische Regeln-Hauptabschnitt D4: Parallelbetrieb von Erzeugungsanlagen mit Verteilernetzen; TOR-D4, Energie-Control Austria: Wien, Austria, 2016.

73. Angelino, R.; Carpinelli, G.; Proto, D.; Bracale, A. Dispersed generation and storage systems for providing ancillary services in distribution systems. In Proceedings of the SPEEDAM 2010, Pisa, Italy, 14-16 June 2010; pp. 343-351.

74. Cerbantes, M.C.; Mantovani, J.R.S.; Femández-Blanco, R.; Ortega-Vazquez, M.A. A nodal pricing approach for reactive power in distribution networks. In Proceedings of the 2017 IEEE PES Innovative Smart Grid Technologies Conference-Latin America (ISGT Latin America), Quito, Ecuador, 20-22 September 2017; pp. 1-6.

75. Calderaro, V.; Galdi, V.; Lamberti, F.; Piccolo, A. A Smart Strategy for Voltage Control Ancillary Service in Distribution Networks. IEEE Trans. Power Syst. 2015, 30, 494-502. [CrossRef]

76. Malamaki, K.D.; Demoulias, C.S. Estimation of Additional PV Converter Losses Operating Under PF $\neq 1$ Based on Manufacturer's Data at PF $=1$. IEEE Trans. Energy Convers. 2019, 34, 540-553. [CrossRef]

77. Hu, Y.-L.; Wu, Y.-K.; Chen, C.-K.; Wang, C.-H.; Chen, W.-T.; Cho, L.-I. A Review of the Low-Voltage Ride-Through Capability of Wind Power Generators. Energy Procedia 2017, 141, 378-382. [CrossRef]

78. Justo, J.J.; Mwasilu, F.; Jung, J.-W. Doubly-fed induction generator based wind turbines: A comprehensive review of fault ride-through strategies. Renew. Sustain. Energy Rev. 2015, 45, 447-467. [CrossRef] 
79. Hossain, M.E. Low voltage ride-through capability improvement methods for DFIG based wind farm. J. Electr. Syst. Inf. Technol. 2018, 5, 550-561. [CrossRef]

80. Banshwar, A.; Sharma, N.K.; Sood, Y.R.; Shrivastava, R. Renewable energy sources as a new participant in ancillary service markets. Energy Strategy Rev. 2017, 18, 106-120. [CrossRef]

81. Berndt, H.; Hermann, M.; Kreye, H.D.; Reinisch, R.; Scherer, U.; Vanzetta, J. Transmission code 2007. Network and System Rules of the German Transmission System Operators. 2007. Available online: https://www.vde.com/resource/blob/937766/bfe325518ace878935966b6efbc493e4/transmissioncode-2007-network-and-system-rules-of-the-german-transmission-system-operators-data.pdf (accessed on 30 December 2019).

82. Yazdanpanahi, H.; Li, Y.W.; Xu, W. A New Control Strategy to Mitigate the Impact of Inverter-Based DGs on Protection System. IEEE Trans. Smart Grid 2012, 3, 1427-1436. [CrossRef]

83. Jing, M.; Jinlong, L.; Zengping, W. An adaptive distance protection scheme for distribution system with distributed generation. In Proceedings of the 2010 5th International Conference on Critical Infrastructure (CRIS), Beijing, China, 20-22 September 2010; pp. 1-4.

84. Sortomme, E.; Venkata, S.S.; Mitra, J. Microgrid Protection Using Communication-Assisted Digital Relays. IEEE Trans. Power Deliv. 2010, 25, 2789-2796. [CrossRef]

85. Dambhare, S.; Soman, S.A.; Chandorkar, M.C. Adaptive Current Differential Protection Schemes for Transmission-Line Protection. IEEE Trans. Power Deliv. 2009, 24, 1832-1841. [CrossRef]

86. Jones, D.; Kumm, J.J. Future Distribution Feeder Protection Using Directional Overcurrent Elements. IEEE Trans. Ind. Appl. 2014, 50, 1385-1390. [CrossRef]

87. Zhang, Y.; Dougal, R.A. Novel Dual-FCL Connection for Adding Distributed Generation to a Power Distribution Utility. IEEE Trans. Appl. Supercond. 2011, 21, 2179-2183. [CrossRef]

88. Ghanbari, T.; Farjah, E. Development of an Efficient Solid-State Fault Current Limiter for Microgrid. IEEE Trans. Power Deliv. 2012, 27, 1829-1834. [CrossRef]

89. Nimpitiwan, N.; Heydt, G.T.; Ayyanar, R.; Suryanarayanan, S. Fault Current Contribution From Synchronous Machine and Inverter Based Distributed Generators. IEEE Trans. Power Deliv. 2007, 22, 634-641. [CrossRef]

90. Basso, T.S.; DeBlasio, R. IEEE 1547 series of standards: Interconnection issues. IEEE Trans. Power Electron. 2004, 19, 1159-1162. [CrossRef]

91. Buigues, G.; Dysko, A.; Valverde, V.; Zamora, I.; Fernández, E. Microgrid Protection: Technical challenges and existing techniques. In Proceedings of the International Conference on Renewable Energies and Power Quality, Bilbao, Spain, 20-22 March 2013; pp. 222-227.

92. Che, L.; Khodayar, M.E.; Shahidehpour, M. Adaptive Protection System for Microgrids: Protection practices of a functional microgrid system. IEEE Electrif. Mag. 2014, 2, 66-80. [CrossRef]

93. Brahma, S.M.; Girgis, A.A. Development of adaptive protection scheme for distribution systems with high penetration of distributed generation. IEEE Trans. Power Deliv. 2004, 19, 56-63. [CrossRef]

94. Casagrande, E.; Woon, W.L.; Zeineldin, H.H.; Svetinovic, D. A Differential Sequence Component Protection Scheme for Microgrids With Inverter-Based Distributed Generators. IEEE Trans. Smart Grid 2014, 5, $29-37$. [CrossRef]

95. Zadeh, H.K. An ANN-Based High Impedance Fault Detection Scheme: Design and Implementation. Int. J. Emerg. Electr. Power Syst. 2005. [CrossRef]

96. Oureilidis, K.O.; Demoulias, C.S. A Fault Clearing Method in Converter-Dominated Microgrids With Conventional Protection Means. IEEE Trans. Power Electron. 2016, 31, 4628-4640. [CrossRef]

97. Gkavanoudis, S.; Oureilidis, K.; Kryonidis, G.; Mauricio, J.M.; Mushtaq, U.; Cvetkovic, M.; Marano, A.; Jerele, M. D3.1 Development of Metrics for Contribution to Fault Clearing and FRT of DRES/BESS. Available online: https://cordis.europa.eu/project/rcn/213757/results/en (accessed on 30 December 2019).

98. Kütt, L.; Saarijärvi, E.; Lehtonen, M.; Mõlder, H.; Vinnal, T. Harmonic load of residential distribution network-Case study monitoring results. In Proceedings of the 2014 Electric Power Quality and Supply Reliability Conference (PQ), Rakvere, Estonia, 11-13 June 2014; pp. 93-98.

99. Chidurala, A.; Saha, T.K.; Mithulananthan, N. Harmonic impact of high penetration photovoltaic system on unbalanced distribution networks-learning from an urban photovoltaic network. IET Renew. Power Gener. 2016, 10, 485-494. [CrossRef]

100. Ismael, S.M.; Abdel Aleem, S.H.E.; Abdelaziz, A.Y.; Zobaa, A.F. State-of-the-art of hosting capacity in modern power systems with distributed generation. Renew. Energy 2019, 130, 1002-1020. [CrossRef] 
101. Sakar, S.; Balci, M.E.; Abdel Aleem, S.H.E.; Zobaa, A.F. Increasing PV hosting capacity in distorted distribution systems using passive harmonic filtering. Electr. Power Syst. Res. 2017, 148, 74-86. [CrossRef]

102. Sakar, S.; Balci, M.E.; Abdel Aleem, S.H.E.; Zobaa, A.F. Integration of large-scale PV plants in non-sinusoidal environments: Considerations on hosting capacity and harmonic distortion limits. Renew. Sustain. Energy Rev. 2018, 82, 176-186. [CrossRef]

103. Liang, X.; Andalib-Bin-Karim, C. Harmonics and Mitigation Techniques Through Advanced Control in Grid-Connected Renewable Energy Sources: A Review. IEEE Trans. Ind. Appl. 2018, 54, 3100-3111. [CrossRef]

104. Li, Y.W.; He, J. Distribution System Harmonic Compensation Methods: An Overview of DG-Interfacing Inverters. IEEE Ind. Electron. Mag. 2014, 8, 18-31. [CrossRef]

105. Gubina, A.F.; Tuerk, A.; Pucker, J.; Taljan, G. Policy framework conditions for provision of ancillary services in a distribution network by distributed RES generation. In Proceedings of the 2015 IEEE Eindhoven PowerTech, Eindhoven, The Netherlands, 29 June-2 July 2015; pp. 1-6.

106. Zotti, G.D.; Pourmousavi, S.A.; Madsen, H.; Poulsen, N.K. Ancillary Services 4.0: A Top-to-Bottom Control-Based Approach for Solving Ancillary Services Problems in Smart Grids. IEEE Access 2018, 6, 11694-11706. [CrossRef]

107. Alkandari, A.; Sami, A.A.; Sami, A. Proposed DSO ancillary service processes considering smart grid requirements. CIRED-Open Access Proc. J. 2017, 2017, 2846-2847. [CrossRef]

108. Soares, T.; Morais, H.; Faria, P.; Vale, Z. Smart grid market using joint energy and ancillary services bids. In Proceedings of the 2013 IEEE Grenoble Conference, Grenoble, France, 16-20 June 2013; pp. 1-6.

109. Ju, G.; Shasha, L.; Chen, C. Research on ancillary service management mechanism in the smart grid. In Proceedings of the 2011 IEEE Power Engineering and Automation Conference, Wuhan, China, 8-9 September 2011; pp. 429-432.

110. Olivares, D.E.; Mehrizi-Sani, A.; Etemadi, A.H.; Cañizares, C.A.; Iravani, R.; Kazerani, M.; Hajimiragha, A.H.; Gomis-Bellmunt, O.; Saeedifard, M.; Palma-Behnke, R.; et al. Trends in Microgrid Control. IEEE Trans. Smart Grid 2014, 5, 1905-1919. [CrossRef]

111. Vandoorn, T.L.; Vasquez, J.C.; Kooning, J.D.; Guerrero, J.M.; Vandevelde, L. Microgrids: Hierarchical Control and an Overview of the Control and Reserve Management Strategies. IEEE Ind. Electron. Mag. 2013, 7, 42-55. [CrossRef]

112. Worighi, I.; Maach, A.; Hafid, A.; Hegazy, O.; Van Mierlo, J. Integrating renewable energy in smart grid system: Architecture, virtualization and analysis. Sustain. Energy Grids Netw. 2019, 18, 100226. [CrossRef]

113. Majzoobi, A.; Khodaei, A. Application of microgrids in providing ancillary services to the utility grid. Energy 2017, 123, 555-563. [CrossRef]

114. Asano, H.; Bando, S. Optimization of a microgrid investment and operation: Energy saving effects and feasibility of ancillary service provision. In Proceedings of the 2009 Transmission \& Distribution Conference \& Exposition: Asia and Pacific, Seoul, Korea, 26-30 October 2009; pp. 1-4.

115. Huo, Y.; Gruosso, G. Hardware-in-the-Loop Framework for Validation of Ancillary Service in Microgrids: Feasibility, Problems and Improvement. IEEE Access 2019, 7, 58104-58112. [CrossRef]

116. Gomes, M.H.; Saraiva, J.T. Allocation of reactive power support, active loss balancing and demand interruption ancillary services in MicroGrids. Electr. Power Syst. Res. 2010, 80, 1267-1276. [CrossRef]

117. Huo, Y.; Barcellona, S.; Gruosso, G.; Piegari, L. Definition and Analysis of an Innovative Ancillary Service for Microgrid Stability Improvement. In Proceedings of the 2018 International Symposium on Power Electronics, Electrical Drives, Automation and Motion (SPEEDAM), Amalfi, Italy, 20-22 June 2018; pp. 990-995.

118. Lamberti, F.; Calderaro, V.; Galdi, V.; Piccolo, A. Ancillary services provided by residential ESSs in LV networks: Assessing the opportunity costs. In Proceedings of the 2017 IEEE Manchester PowerTech, Manchester, UK, 18-22 June 2017; pp. 1-6.

119. Christakou, K. A unified control strategy for active distribution networks via demand response and distributed energy storage systems. Sustain. Energy Grids Netw. 2016, 6, 1-6. [CrossRef]

120. Coppo, M.; Cappelletto, F.; Caldon, R.; Turri, R.; Natale, N.; Pilo, F.; Pisano, G.; Soma, G.G. Ancillary services by DG and storage systems in distribution networks for energy market participation. In Proceedings of the 2016 AEIT International Annual Conference (AEIT), Capri, Italy, 5-7 October 2016; pp. 1-6. 
121. Mwasilu, F.; Justo, J.J.; Kim, E.-K.; Do, T.D.; Jung, J.-W. Electric vehicles and smart grid interaction: A review on vehicle to grid and renewable energy sources integration. Renew. Sustain. Energy Rev. 2014, 34, 501-516. [CrossRef]

122. Ferro, G.; Laureri, F.; Minciardi, R.; Robba, M. An optimization model for electrical vehicles scheduling in a smart grid. Sustain. Energy Grids Netw. 2018, 14, 62-70. [CrossRef]

123. Sarabi, S.; Davigny, A.; Courtecuisse, V.; Riffonneau, Y.; Robyns, B. Potential of vehicle-to-grid ancillary services considering the uncertainties in plug-in electric vehicle availability and service/localization limitations in distribution grids. Appl. Energy 2016, 171, 523-540. [CrossRef]

124. Rongrong, Y.; Yao, C.; Xing, H.; Parra, H.Z.D.L. Economic evaluation for EVCS with ancillary service provision capability. In Proceedings of the 2014 IEEE Conference and Expo Transportation Electrification Asia-Pacific (ITEC Asia-Pacific), Beijing, China, 31 August-3 September 2014; pp. 1-5.

125. Zecchino, A.; Knezović, K.; Marinelli, M. Identification of conflicts between transmission and distribution system operators when acquiring ancillary services from electric vehicles. In Proceedings of the 2017 IEEE PES Innovative Smart Grid Technologies Conference Europe (ISGT-Europe), Torino, Italy, 26-29 September 2017; pp. 1-6.

126. Ruester, S.; Schwenen, S.; Batlle, C.; Pérez-Arriaga, I. From distribution networks to smart distribution systems: Rethinking the regulation of European electricity DSOs. Util. Policy 2014, 31, 229-237. [CrossRef]

127. Ferrante, A.; Constantinescu, N.; Jackson, J.A. Lines of Convergence: R\&D for Transmission and Distribution: Coordination and the Regulatory Challenge. IEEE Power Energy Mag. 2015, 13, 52-59.

128. Eid, C.; Bollinger, L.A.; Koirala, B.; Scholten, D.; Facchinetti, E.; Lilliestam, J.; Hakvoort, R. Market integration of local energy systems: Is local energy management compatible with European regulation for retail competition? Energy 2016, 114, 913-922. [CrossRef]

129. Fonseca, N.; Silva, J.; Silva, A.; Sumaili, J.; Seca, L.; Bessa, R.; Pereira, J.; Matos, M.; Matos, P.; Morais, A.C.; et al. EvolvDSO grid management tools to support TSO-DSO cooperation. In Proceedings of the CIRED Workshop 2016, Helsinki, Finland, 14-15 June 2016; pp. 1-4.

130. Rivero, E.; Six, D.; Mallet, P.; Sebastian-Viana, M.; Stromsather, J.; Baron, M. evolvDSO: Assessment of the future roles of DSOs, future market architectures and regulatory frameworks for network integration of DRES. In Proceedings of the 23rd International Conference on Electricity Distribution (CIRED), Lyon, France, 15-18 June 2015; p. 5.

131. Tapscott, D.; Tapscott, A. Blockchain Revolution: How the Technology Behind Bitcoin is Changing Money; Business, and the World: Baltimore, MD, USA, 2016.

132. Gerard, H.; Rivero, E.; Six, D. Basic Schemes for TSO-DSO Coordination and Ancillary Services Provision. Available online: http://smartnet-project.eu/wp-content/uploads/2016/12/D1.3_20161202_V1.0.pdf (accessed on 30 December 2019).

133. Demoulias, C.; Spyros, G.; Mauricio, J.M.; Konstantinos, G.; Christos, D.; Mushtaq, U.; Cvetkovic, M.; Schneider, C.; Damböck, R.; Lampridis, D.; et al. D2.1 Description of Metrics Developed with Respect to Transient and Dynamic Response and Report on the Review of the Respective Current Grid Codes. Available online: https://cordis.europa.eu/project/rcn/213757/results/en (accessed on 30 December 2019).

134. Angioni, A.; Castello, P.; Ferrari, P.; Monti, A.; Muscas, C.; Pau, M.; Pegoraro, P.A.; Peretto, L.; Ponci, F.; Rinaldi, S.; et al. Phasor Measurement Units and Wide Area Monitoring Systems; Academic Press: Cambridge, MA, USA, 2016; pp. 1-286.

135. Sun, Q.; Li, H.; Ma, Z.; Wang, C.; Campillo, J.; Zhang, Q.; Wallin, F.; Guo, J. A Comprehensive Review of Smart Energy Meters in Intelligent Energy Networks. IEEE Internet Things J. 2016, 3, 464-479. [CrossRef]

136. Yuan, Z.; Hesamzadeh, M.R. Hierarchical coordination of TSO-DSO economic dispatch considering large-scale integration of distributed energy resources. Appl. Energy 2017, 195, 600-615. [CrossRef]

137. Zipf, M.; Möst, D. Cooperation of TSO and DSO to provide ancillary services. In Proceedings of the 2016 13th International Conference on the European Energy Market (EEM), Porto, Portugal, 6-9 June 2016; pp. 1-6.

138. European Distribution System Operators for Smart Grids. Coordination of Transmission and Distribution System Operators: A Key Step for the Energy Union. Available online: https://www.edsoforsmartgrids.eu/wpcontent/uploads/public/Coordination-of-transmission-and-distribution-system-operators-May-2015.pdf (accessed on 30 December 2019).

139. Yang, T. ICT technologies standards and protocols for active distribution network. In Smart Power Distribution Systems; Yang, Q., Yang, T., Li, W., Eds.; Academic Press: Cambridge, MA, USA, 2019; pp. 205-230. 
140. SMA Technical Information. Measurement Accuracy-Energy Values and Efficiency for PV Inverter Sunny Boy and Sunny Mini Central. Available online: http://files.sma.de/dl/7418/Messgenau-UEN092520.pdf (accessed on 30 December 2019).

141. Eto, E.S.T.; Smith, M.T.; Buckner, H.; Kirkham, F.; Tuffner, D. Schoenwald, Scoping Study on Research and Development Priorities for Distribution-System Phasor Measurement Units; Ernest Orlando Lawrence Berkeley National Laboratory: Berkeley, CA, USA, 2016.

142. Goldstein, A. 2014 NIST Assessment of Phasor Measurement Unit Performance; NIST National Institute of Standards and Technology: Gaithersburg, MD, USA, 2016.

143. IEEE Standard for Synchrophasor Measurements for Power Systems-Amendment 1: Modification of Selected Performance Requirements. In IEEE Std C37.118.1a-2014 (Amendment to IEEE Std C37.118.1-2011); IEEE: Piscataway, NJ, USA, 2014; pp. 1-25.

144. Merino, J.; Gómez, I.; Turienzo, E.; Madina, C.; Cobelo, I.; Morch, A.; Saele, H.; Verpoorten, K.; Puente, E.R.; Häninnen, S.; et al. Ancillary Service Provision by RES and DSM Connected at Distribution Level in the Future Power System. Available online: http://smartnet-project.eu/wp-content/uploads/2016/12/D1-1_ 20161220_V1.0.pdf (accessed on 30 December 2019).

145. Mateo, C.; Frías, P.; Cossent, R.; Sonvilla, P.; Barth, B. Overcoming the barriers that hamper a large-scale integration of solar photovoltaic power generation in European distribution grids. Sol. Energy 2017, 153, 574-583. [CrossRef]

146. Castagneto Gissey, G.; Dodds, P.E.; Radcliffe, J. Market and regulatory barriers to electrical energy storage innovation. Renew. Sustain. Energy Rev. 2018, 82, 781-790. [CrossRef]

147. Zame, K.K.; Brehm, C.A.; Nitica, A.T.; Richard, C.L.; Schweitzer Iii, G.D. Smart grid and energy storage: Policy recommendations. Renew. Sustain. Energy Rev. 2018, 82, 1646-1654. [CrossRef]

148. Verzijlbergh, R.A.; De Vries, L.J.; Dijkema, G.P.J.; Herder, P.M. Institutional challenges caused by the integration of renewable energy sources in the European electricity sector. Renew. Sustain. Energy Rev. 2017, 75, 660-667. [CrossRef]

149. I Pérez-Arriaga, A.B. A Framework for Redesigning Distribution Network Use of System Charges Under High Penetration of Distributed Energy Resources New principles for New problems. In CEEPR WP 2014-006; MIT Centre for Energy and Environmental Policy Reseach (MIT CEEPR): Cambridge, CA, USA, 2014.

150. Fontaine, A.; Caetano, B.; Olmos, L.; Rodilla, P.; Loureiro, R. Developments Affecting the Design of Long-Term Markets. Available online: http://market4res.eu/wp-content/uploads/D3.1_20151008_final.pdf (accessed on 30 December 2019).

151. Guggilam, S.S.; Zhao, C.; Dall'Anese, E.; Chen, Y.C.; Dhople, S.V. Optimizing Power-Frequency Droop Characteristics of Distributed Energy Resources. IEEE Trans. Power Syst. 2018, 33, 3076-3086. [CrossRef]

152. The Grid Code; National Grid Electricity System Operator: Warwick, UK, 2019.

153. Shivashankar, S.; Mekhilef, S.; Mokhlis, H.; Karimi, M. Mitigating methods of power fluctuation of photovoltaic (PV) sources-A review. Renew. Sustain. Energy Rev. 2016, 59, 1170-1184. [CrossRef]

154. Basak, P.; Chowdhury, S.; Halder nee Dey, S.; Chowdhury, S.P. A literature review on integration of distributed energy resources in the perspective of control, protection and stability of microgrid. Renew. Sustain. Energy Rev. 2012, 16, 5545-5556. [CrossRef]

155. IEEE Recommended Practice and Requirements for Harmonic Control in Electric Power Systems. In IEEE Std 519-2014 (Revision of IEEE Std 519-1992); IEEE: Piscataway, NJ, USA, 2014; pp. 1-29.

156. IEC TR 61000-3-6. Electromagnetic Compatibility (EMC)-Part 3-6: Assessment of Emission Limits for Distorting Loads in MV and HV Power Systems; International Electrotechnical Commission (IEC): Geneva, Switzerland, 2008.

157. Enable Ancillary Services by Renewable Energy Sources (EASY-RES) Horizon 2020 EU Project. Available online: https://www.easyres-project.eu/ (accessed on 30 December 2019).

(C) 2020 by the authors. Licensee MDPI, Basel, Switzerland. This article is an open access article distributed under the terms and conditions of the Creative Commons Attribution (CC BY) license (http://creativecommons.org/licenses/by/4.0/). 